\title{
Confirmation of Subjective Wellbeing Set-points: Foundational for Subjective Social Indicators
}

\begin{tabular}{|c|c|}
\hline $\begin{array}{l}\text { The Names and Order } \\
\text { of Authors: }\end{array}$ & $\begin{array}{l}\text { Tanja Capic } \\
\text { Ning Li } \\
\text { Robert A Cummins }\end{array}$ \\
\hline $\begin{array}{l}\text { Corresponding Author } \\
\text { Contact Details: }\end{array}$ & $\begin{array}{l}\text { Ms Tanja Capic } \\
\text { Address: } \\
\text { Deakin University } \\
221 \text { Burwood Highway } \\
\text { Burwood } \\
\text { Victoria } 3125 \text { Australia } \\
\text { Email: } \\
\text { tanja.capic@deakin.edu.au } \\
\end{array}$ \\
\hline \multirow[t]{2}{*}{$\begin{array}{l}\text { Other Author } \\
\text { Addresses: }\end{array}$} & $\begin{array}{l}\text { Dr Ning Li } \\
\text { Address: } \\
\text { Melbourne Institute of Applied Economic and } \\
\text { Social Research } \\
\text { Level 5, Faculty of Business and Economics Building, } \\
\text { 111 Barry Street, } \\
\text { The University of Melbourne } \\
\text { Victoria 3010 Australia } \\
\text { Email: } \\
\text { ning.li@ unimelb.edu.au }\end{array}$ \\
\hline & $\begin{array}{l}\text { Prof. Robert A Cummins } \\
\text { Address: } \\
\text { Deakin University } \\
221 \text { Burwood Highway } \\
\text { Burwood } \\
\text { Victoria } 3125 \text { Australia } \\
\text { Email: } \\
\text { robert.cummins@deakin.edu.au }\end{array}$ \\
\hline
\end{tabular}




\section{Confirmation of Subjective Wellbeing Set-points: Foundational for Subjective Social Indicators}

The usefulness of subjective wellbeing (SWB) as a social indicator rests on understanding what controls its level when measured through self-report data. While the theory of SWB homeostasis provides a cogent explanatory framework for the control processes, this theory relies on set-points, and direct evidence for their existence rests on a single study. Cummins, Li, Wooden, and Stokes (2014) demonstrated a normal range of setpoints between 71 and 90 percentage points on a 0-100 scale, using data on General Life Satisfaction (GLS). These findings are consistent with homeostasis theory, which proposes that set-points account for the normal positivity of SWB while its stability is accounted for by homeostatic processes. The current paper extends the first report in two ways. First, by replicating the range of set-points using a different data set. Second, by extending the findings to Homeostatically Protected Mood (HPMood), which is proposed to be the basic psychological molecule that homeostasis seeks to protect. Participants completed between 5 and 10 surveys. Data preparation involved the iterative elimination of scores based on significant deviation from their over-time mean score. It is confirmed that GLS and HPMood set-points are both normally distributed between 75 and 90 points. These results offer further support for the usefulness of SWB as a social indicator.

Keywords. Subjective social indicators, Subjective Wellbeing, Set-points, Homeostasis, Homeostatically Protected Mood, Global Life Satisfaction. 


\section{Introduction}

The year 2016 marked a 50-year history of social indicators, celebrated by a special issue of Social Indicators Research (Land \& Michalos, 2016). The notable foundation publication by Bauer (1966) and colleagues is a substantial work that well represents the thinking of that time. They proposed that the aim of social indicators is to measure the relative goodness of societies, such that societal progress in these terms could be assessed. The variables they chose to represent goodness were economic, either as actual money or the goods and services that money could buy. Such objective social indicators were acceptable in having high face validity, measurement validity and reliability. Their counterpoints, in the form of subjective social indicators, were barely acknowledged. Indeed, the scientific worth of subjective indicators was viewed with scepticism. Being considered unreliable they received short shrift (Cummins, 2016a).

In fact, the reliability of subjective wellbeing measures had been demonstrated some 36 years previously. The psychologist G. B. Watson (1930) had reported that self-ratings of happiness, measured using a printed rating scale, correlated .81 with a composite score comprising other subjective indices. Watson concluded that the general level of happiness can be measured reliably. Numerous other researchers followed his lead and it was soon discovered that measures of mood happiness were not only reliable but also surprisingly stable over time. For example, just four years later (Hartmann, 1934) obtained a test-retest reliability of .70 with two measurements a month apart, while (Wessman \& Ricks, 1966, p. 103) reported that happiness-related measures taken 2 years apart correlated .67.

Perhaps Bauer and colleagues were unaware of this research, or perhaps they considered it irrelevant. The general purpose of social indicators has been elaborated by Land (2015) as: To monitor change over time; to enlighten the public through social reporting; and to causally link changes in the measured variables to consequences for societal functioning. It is this latter aim which is key to getting the attention of policy makers concerned with societal functioning. The functional relevance of subjective indicators must be evident and, clearly, in 1966 it was not. Even now this has been poorly achieved.

In order for social indicators to be useful for policy, Land (1983) has proposed the following conditions be met: (a) agreement about what needs improving; (b) agreement about what "getting better" means; and (c) that the relevant indicators can be reliably and validly aggregated to inform the level at which the policy is defined. In applying these criteria it becomes clear why the subjective social indicators have failed to make the grade. Crucially, at the level of populations, there is little understanding about the policy implications of higher or lower levels of subjective wellbeing (SWB). So a crucial, missing element is understanding the mechanisms that cause SWB to rise and fall at the level of individuals. While there is now a vast literature on this topic, there is little consensus and, consequently, no clear path to understanding the implications of SWB changes for social policy.

Contrasting the above description with the objective social indicator of wealth provides a stark contrast. The causal linkage of wealth to better societal function is selfevident. Money is the most flexible resource (for a review see Cummins, 2000) for wellbeing generally. When properly applied, money can fix most of what needs improving, there is general agreement that 'more is better', various manifestations of wealth can be aggregated to form a robust index, and the mechanism whereby wealth translates to improved societal 
conditions is obvious. In summary, money is important. The level of national happiness is not important, at least to policy makers. The social sciences need to lift their game.

We propose that, fundamental to the achievement of social policy relevance, is understanding the composition and properties of SWB; most especially what makes its level rise or fall. Significant advances have been made to this end. First, it is clear that the composition of SWB is dominated by mood affect (Blore, Stokes, Mellor, Firth, \& Cummins, 2011; Davern, Cummins, \& Stokes, 2007; Tomyn \& Cummins, 2011). This mood affect differs from emotion affect. Emotion is the highly variable affect generated in response to experiences (Branden, 1966; Lazarus, 1991). Mood, on the other hand, is far more stable and more strongly linked to overall wellbeing (Forgas, 1991; Halle, 2003).

Second, it is now understood that the mood in SWB comes from Homeostatically Protected Mood (HPMood), which is proposed as the output of a genetically-determined setpoint for each person (for a review see Cummins, 2016b). This mood affect is, thus, unchanging and constitutes an individual difference. Indeed, HPMood not only accounts for most of the variance in subjective wellbeing but also accounts for much variance within other forms of self-report data derived from scales such as self-esteem, optimism, and perceived control (Lai \& Cummins, 2013). In fact, it seems a fair bet that HPMood is the 'crud factor' recognised by Meehl (1990) as providing the shared variance causing positive self-report measures to correlate with one another at .3 to .6 with such predictability.

Confusing this picture of HPMood set-points is the claim, made by various authors, that set-points are not 'set' in terms of being stable, but can change. Their evidence for this assertion relies on the observation that levels of measured SWB change over time, coupled with the idea that measured SWB represents the respondent's set-point (eg. Diener, Kanazawa, Suh, \& Oishi, 2015; Easterlin, 2005; Headey, 2010). While we agree that levels of SWB change over time, we dispute the view that measured SWB represents set-points.

At the heart of understanding why SWB and set-points are different is the construct of homeostasis. This proposes that HPMood is the normal, constant, mood content of SWB. Thus, under resting conditions, with low levels of emotion being present, HPMood dominates the affective content of SWB. However, this HPMood is merely a weak background affect. Imposed on this background are the 'signals' of emotion, which are generated in response to relevant percepts. These sources of affect are likely to be stronger than HPMood. Indeed this is their design, directing attention to the percept (Frijda, 1986). Thus, when emotions occur, experienced affect will reflect emotion rather than mood, and measured SWB will be at a level different from the HPMood set point.

Such perturbations of SWB away from set-point are most commonly acute, as the various mechanisms of SWB homeostasis act to diminish the strength of the emotional response (Cummins, 2016b), and so the affective experience once again returns to approximate set-point. However, long-term changes in SWB can also occur. They do not represent a change in set-point. They represent a persistent defeat of homeostasis due to the continued presence of a powerful stressor, such as may be generated by unemployment, persecution, pain, etc. Such chronic change represents pathology and is a harbinger of depression (Cummins, 2010).

From this understanding it is evident that a response to SWB will contain both HPMood and emotional affect. If the emotion is under homeostatic control, then the SWB 
response will approximate the HPMood set-point. If, however, emotion is dominating the affective experience then, in order to obtain an estimate of set-point, the mood component must be separated from emotion.

The first evidence that this can be achieved was published by (Cummins et al., 2014). The data employed were derived from the Household, Income and Labour Dynamics in Australia Survey, using responses to a Global Life Satisfaction (GLS) question over 10 consecutive years. The GLS question asked: 'All things considered, how satisfied are you with your life?' In order to use these data to demonstrate set-points, individual scores that reflected emotion, rather than mood, were eliminated using an iterative procedure described both in that paper and in the method section below. Based on this technique, SWB set-points were found to be normally distributed between 71 and 90 points on a standardized 0-100 point scale. Moreover, the range within which SWB values are normally found around each set-point was determined as between 9 to 10 points on either side of each set-point, or a range of approximately 19 points.

If this result can be replicated, it will not only confirm the existence of set-points but also indicate the means by which measured SWB can be used as a social indicator. That is, the proportion of SWB scores that lie below the normal range for HPMood set-points are an indicator of the relative incidence of homeostatic defeat and susceptibility to depression (Cummins, 2010). To this end the current study has two aims. First, to replicate the cited findings on set-points (Cummins et al., 2014) using a different data set. Second, to extend the investigation into the mood core of SWB characterized as HPMood. While it is proposed that HPMood is the stable component of SWB, this stability of HPMood over time has not been empirically determined. In summary, this study will test for stability in HPMood, determine whether set-points can be established for both GLS and HPMood, and examine whether the derived set-points are comparable.

In the following description, references to the first study (Cummins et al., 2014) will be designated as Study1. References to the current study will be designated as Study2. In addition, the references to GLS results in Study1 and 2 will be referred to as GLS1 and GLS2, respectively. References to GLS in general will remain as GLS. Thus, it is hypothesised that:

1. GLS2 and HPMood set-points will lie between 70.1 and 90 points.

2. GLS2 and HPMood set-points will be normally distributed around the mean set-point for the sample.

3. The mean set-point-range for both GLS2 and HPMood will be around 19 points.

\section{Method}

In order to estimate the range of set-points, and the range around each set-point which normally contains SWB (SWB-set-point-range), Study2 replicates the method of Study1 using a different sample. The method is described within five sections. The first three sections, '2.1 Participants', '2.2 Measures' and '2.3 Data preparation', describe the sample selection and the measures used in Study2 compared to those used in Study1. The fourth section, '2.4 Analytic rationale', explains the four assumptions underpinning the estimation of set-points and SWB-set-point-ranges using self-report GLS2 and HPMood data. These assumptions are similar to those described in Study1. Section '2.5 Procedure', explains the process by which the estimation of set-points and SWB-set-point-ranges is achieved and 
notes the procedural differences between the two studies. The final section '2.6 Hypothesis testing' describes the steps in testing each of the hypotheses. At the end of this section, the list of criteria for the estimation of set-points and SWB-set-point-ranges is summarized.

The following rules for nomenclature will be employed throughout the following text:

- Within-person standard deviation (w-pSD): The standard deviation calculated using the remaining scores for each person following data-stripping.

- Within-person standard deviation mean (w-pSD mean): The mean of all within-person standard deviations.

- Personal set-point: The mean of the remaining scores for each person following datastripping.

- The SWB-set-point range: Defined by (4x w-pSD), this is the range within which measures of SWB are found for each person following data-stripping.

- Range of set-points: The estimated range over which set-points exist.

\subsection{Participants}

The samples used for each of the two studies are very different. Study1 was a fullyfunded, longitudinal investigation. The retention rate during the 10 annual surveys was high, approaching 96\% (N. Watson \& Wooden, 2012). The final sample used for Study1 comprised 7,282 participants who had each completed 10 consecutive surveys.

Study 2 was conducted using follow-up data from a study funded to be cross-sectional, as the Australian Unity Wellbeing Index. Beginning in 2001, each of the subsequent 25 waves of data collection, conducted over a period of 12 years, involved a newly recruited sample. At the end of each survey, participants were asked whether they would be willing to enter a longitudinal study. Those who agreed joined a pool of like-minded participants from previous surveys, and all of these people received an annual follow-up survey by surface mail. Only one invitation was sent on each occasion and non-respondents were simply dropped from the longitudinal study.

The final longitudinal sample available to Study 2 contained 5,921 people, each of whom had completed two or more surveys. Of those, only 78 participants completed all 10 surveys (see Table 1). Since this number is too small to conduct the planned analyses, the usable sample size was increased by reducing the required number of consecutive surveys for each person. Deciding the number of surveys each participant must complete in order to optimize the usable sample involves a balance between two optimal requirements.

The first requirement is a reliable estimate of each person's set-point. This reliability is enhanced by each person completing as many surveys as possible. The second requirement is a reliable estimate of the range of set-points within the sample. Such analysis involves a whole-study perspective, where the values are averaged across people. This reliability of estimating the range of set-points is enhanced by increasing the number of people remaining for the final analysis. In balancing these two requirements, it was decided to set the minimum number of surveys completed by each person at five. 
Table 1 Number of surveys completed by participants

\begin{tabular}{|c|c|c|c|c|}
\hline $\begin{array}{r}\text { Total number of } \\
\text { surveys } \\
\text { completed by } \\
\text { participants }\end{array}$ & $\begin{array}{l}\text { Number of } \\
\text { participants }\end{array}$ & $\begin{array}{r}\% \text { of total } \\
\text { sample }\end{array}$ & Cumulative \% & * Mean Age \\
\hline 5 & 359 & $31.2 \%$ & $31.2 \%$ & 59 \\
\hline 6 & 183 & $15.9 \%$ & $47.1 \%$ & 57 \\
\hline 7 & 221 & $19.2 \%$ & $66.3 \%$ & 59 \\
\hline 8 & 150 & $13.0 \%$ & $79.3 \%$ & 59 \\
\hline 9 & 160 & $13.9 \%$ & $93.2 \%$ & 61 \\
\hline 10 & 78 & $6.8 \%$ & $100.0 \%$ & 59 \\
\hline Total & 1,151 & $100 \%$ & & \\
\hline
\end{tabular}

As shown in Table 1, the sample for Study2 comprised the 1,151 respondents who had completed at least 5 surveys. This group represents $19.4 \%$ of the total 5,921 people who had completed two or more surveys. The sample contains 660 females $(57.3 \%)$ and 491 $(42.7 \%)$ males; a gender proportion comparable to Study1 ( $\mathrm{F}=52.7 \%$; $\mathrm{M}=47.3 \%)$. However, the mean age of participants in Study2 is around 15 years older than in Study1, where the age of participants ranged from 15 to $101(\mathrm{M}=43.80 ; \mathrm{SD}=18.36)$. In Study2, the age of respondents at recruitment ranged from 18 to 88 years $(\mathrm{M}=58.71 ; \mathrm{SD}=12.88)$. There was no systematic change in age between participants depending on the number of surveys they completed (Table 1). Thus, the difference in age between Study1 and Study2 partly reflects the different minimum age requirement at recruitment, but is mostly due to the continued participation of older adults in the AUWI Survey.

In terms of other demographic characteristics in Study2, $48.7 \%$ of the sample are either married or living together, $26.1 \%$ are never married, $13.6 \%$ are widowed and $10.9 \%$ are separated or divorced. While these proportions are comparable to the general Australian population (Australian Bureau of Statistics, 2012), a higher than normal proportion are retired (Study2: $61.5 \%$ vs Australian population: $26.3 \%$ ), and a lower proportion are full-time employed (Study2: 24.0\% vs Australian population 59.7\%).

In summary, people forming the final sample for Study2 had each completed from 5 to 10 surveys. However, these completed surveys were not always consecutive. This irregularity contrasts with the Study1 sample, where all participants had completed 10 consecutive surveys. In addition, the people in Study2 were older and less representative of the general population. Clearly, the participants for Study 2 have a more complex character than those of Study1.

\subsection{Measures}

In Study2, participants received a follow-up questionnaire in the mail about once a year. Each questionnaire comprised approximately 100 questions concerning various aspects of subjective life quality, followed by 15 demographic questions. Only responses to General Life Satisfaction (GLS2) and Homeostatically Protected Mood (HPMood) were used in Study2. 


\subsubsection{Global Life Satisfaction}

GLS is a single-item asking about general life satisfaction. GLS1 is worded: "All things considered, how satisfied are you with your life?" and GLS2 is worded: "How satisfied are you with your life as a whole?" For both GLS1 and GLS2, responses are recorded on a 0-10 response scale. During the course of Study2, the anchor points on the scale were changed from bipolar ("completely dissatisfied/completely satisfied") to unipolar ("not satisfied at all/completely satisfied"). This change improved the interpretation of the response scale without affecting the group mean (International Wellbeing Group, 2013).

\subsubsection{Homeostatically Protected Mood}

The HPMood measure, only available for Study2, comprises three questions. Two of these as "How happy do you generally feel?" and "How content do you generally feel?" measure mood valence and are asked across all surveys. The third question measures the level of emotional arousal using, in various surveys, one of the three affects as "alert", "active" or "excited". HPMood then comprises a combination of the two valence items plus which ever arousal item was used in the corresponding survey. In constructing HPMood, priority was given to the adjective "alert" based on the analysis by (Tomyn, 2008), which showed that of the three affects, "alert" accounted for most unique variance in GLS. Responses are recorded on an 11-point scale, from 0 (Not at all) to 10 (Extremely).

\subsection{Data Preparation}

All GLS2 and HPMood scores are standardized to a 0-100 percentage-point scale for easier interpretation. All cases were initially examined for missing values and acquiescence response bias (International Wellbeing Group, 2013). Respondents with less than 5 scores remaining due to missing values were excluded from the analysis. This involved 4 out of $1,151(0.4 \%)$ respondents missing GLS2 scores and $199(17.3 \%)$ respondents missing one of the HPMood affect scores. Also excluded were $22(1.9 \%)$ participants who consistently scored 100 on GLS2 and $2(0.2 \%)$ participants who consistently scored 100 on HPMood. These exclusions control for social acquiescence bias. The final GLS2 and HPMood samples comprise 1,125 (97.7\%) and $950(82.5 \%)$ respondents yielding 7,674 and 6,341 responses, respectively.

\subsection{Analytic rationale}

The estimation of set-points and SWB-set-point-ranges for GLS2 and HPMood is premised on four assumptions. These assumptions describe the logic by which the set-points and the SWB-set-point-ranges for GLS2 and HPMood can be derived from raw scores. Table 2 lists the four assumptions in Column 1, with an explanation in Column 2.

Table 2 Assumptions and Explanations

\section{Assumptions:}

1. Each GLS2 and HPMood response represents a score being one of two types:

(a) Scores that are representative of people's SWB-set-point-range and (b) Scores that lie outside their SWB-setpoint-range, referred to as outliers. It is

\section{Explanations:}

1. The estimation of each personal SWBset-point-range, for both GLS2 and HPMood, is achieved through iterative data-stripping, described in the ' 2.5 Procedure' section. 
assumed that by removing the outliers for each person, the residual scores will best approximate that person's SWB-setpoint-range.

2. The extent to which each estimate of setpoint and SWB-set-point-range reflects each person's true set-point and setpoint-range depends on the proportion of responses made under homeostatic control.
2. If a person responded under homeostatic control each time they completed the survey, their aggregated scores over time are expected to show small variation from their true set-point. That is, their scores will all fall within their personal normal range defined as two withinperson standard deviations (w-pSDs) around their mean. Thus, the mean and the normal range derived from such scores will closely reflect their true setpoint and set-point-range, respectively.

People who were experiencing homeostatic failure at the time of making a response are expected to generate that response as an outlier, beyond their true set-point-range. The inclusion of outliers in an aggregate for that person will result in an increased w-pSD and a mean that is higher or lower than their true set-point. The more frequently outliers are included in the aggregate for a person, the more severely their mean and w-pSD will deviate from their true set-point and set-point-range.
3. Clusters of GLS2 and HPMood scores showing the lowest within-person variations over time (lowest w-pSDs) will best approximate the set-points and SWB-set-point-ranges for the sample.
3. Within the Theory of SWB Homeostasis, small variations in SWB reflect a normally functioning homeostatic system as it maintains SWB and HPMood close to each person's set-point. Due to this restricted range, low w-pSDs signal the close proximity of people's scores to their set-point. Therefore, the lowest wpSDs are used to provide the best estimate of both set-points and SWB-setpoint-ranges.
4. Within the range of set-points, the setpoints will be normally distributed
4. The theory of SWB Homeostasis proposes that set-points are normally 


\section{Assumptions:}

around the mean of the range.

\section{Explanations:}

distributed within a population as an individual difference. Thus, due to variation in the level of set-points between people, when measured over time, the maintenance of homeostatic control will create a normal distributions of set-points (Cummins et al., 2014). Moreover, in Study2, since HPMood is proposed to be the primary constituent of GLS (Cummins, 2010), the normal distribution of set-points will be evident for both variables.

Note: The assumptions in this study are based on those from (Cummins et al., 2014).

\subsection{Procedure}

The iterative data-stripping process, as conceptualised from Study1, involves an initial grouping of people into numerical categories based on each person's raw-score mean. This categorization is performed separately for both GLS2 and HPMood. Then, the raw scores within each category are treated as a sample representing that category. These raw scores are used to estimate the mean of raw scores and a mean of w-pSDs for each category. These will be used to define a normative range for each category, as explained below.

Numerical categories are defined by a width of 5-points. This width has been chosen as the smallest width that yields a reliable number of individual scores within each category. The single exception is the category $0-45$ points, created to accommodate the very few people with a mean score below 45 points.

The process of determining the mean set-point and SWB-set-point-range for each category is iterative. It is performed in the following way:

1. The data used in each category are the raw-scores provided by category members.

2. These raw scores are used to generate a category mean and SD.

3 . The SD is calculated as the average w-pSD of the people in the category.

4. The $2 \mathrm{xSD}$ range on either side of the mean then describes the "normal range' of scores for the category.

5. Scores lying outside this normal range are regarded as outliers.

These outlying raw scores are then eliminated for the second iteration. Following each such elimination the number of people remains the same. However, if a person loses more than half of their original number of raw scores at any iteration, that person and their raw scores are removed from further analysis. These removed scores are referred to as the nonreliable residual scores ( $\mathrm{n}-\mathrm{rRS}$ ).

The elimination procedure for n-rRSs differs from that used in Study1 in two respects. First, in Study1, all respondents contributed equal number of scores. The n-rRSs were identified when a number of remaining scores for any person became less than 4. In Study2 respondents contributed different number of initial scores, so the n-rRS identification is made 
for each person when the number of their remaining scores falls below half of their initial number. For example, two people who contributed 5 and 10 scores each will meet the n-rRS criterion when the number of their remaining scores falls below 3 and 5 scores, respectively. Second, in Study1, the n-rRSs were only identified, and therefore excluded, after the last iteration. In Study 2 these scores were excluded after each iteration. This prevents the n-rRSs from influencing the mean and normative range of their respective categories throughout the remaining iterations.

Following the above procedures, the second iteration uses the raw scores remaining from the first iteration. The next step is to establish whether the people in each category still belong. People who have lost one or more raw scores in the first iteration will now have a changed mean. So a mean of the remaining raw scores is now re-calculated for each person. There are then two possible courses of action:

(a) If the new mean continues to lie in its original category, then all the scores for that person will remain in that category.

(b) If the new mean now lies in a different category, the scores for that person will be shifted to that category.

After all miss-fitting personal means have been re-allocated to appropriate categories, and people have been eliminated as described, data-stripping continues as for the first iteration. At the last iteration of the data-stripping process, the mean of raw scores in a category reflects an average set-point for people in that category. Likewise, the mean of wpSD in each category, reflects an average within-person variation of scores for people in that category.

In summary of the above process, each iteration identifies and removes outliers by comparing the remaining raw scores in each category against their own normative range. This process is repeated until no further outliers can be identified. At this point, the mean and the normative range in each category will best approximate the set-point and SWB-set-pointranges for people in those categories, respectively. These GLS2 and HPMood data remaining after the final iteration are used to test the hypotheses.

\subsection{Hypothesis testing}

\section{Hypothesis 1: Both the GLS2 and HPMood set-points will lie between 70.1 and 90 points.}

This hypothesis is tested by examining the average within-person standard deviations (w-pSD) within categories. This testing is done in two stages. The first stage examines the degree of commonality in w-pSD means between the three variables, GLS1, GLS2 and HPMood. This is done by visually comparing the magnitudes of GLS1 and GLS2 w-pSD means across the 12 categories from 0 to 100 points. The same comparison is then made for GLS2 and HPMood, to determine whether HPMood follows the similar pattern. In the second stage, the w-pSD means for GLS2 and HPMood are separately examined within each of the 12 categories, to allow identification of the categories with the lowest w-pSD means. A cluster of categories that have the lowest w-pSDs will be assumed to comprise set-points. Significance will be tested using analysis of variance and post-hoc analysis. 
Hypothesis 2: GLS2 and HPMood set-points will be normally distributed around the mean set-point for the sample.

This hypothesis will be tested using data within the estimated range of set-points. The procedure is done in three steps. First, the personal means, which lie within the estimated range of set-points, are used to calculate the mean set-point for the sample. Second, a standard deviation (SD) of personal means is calculated for both GLS2 and HPMood. Finally, the confidence intervals for each distribution of set-point are calculated using the personal means which lie within 3 SDs around the mean set-point for the sample. These are expected to capture $99.7 \%$ of the sample's set-points. The normality of these distributions can be concluded if they approximate the bell curve.

\section{Hypothesis 3: The mean SWB-set-point-range for both GLS2 and HPMood will be around 19 points.}

The mean SWB-set-point-range and the mean set-point are calculated from the data of individuals who are included within the range of set-points. First the mean set-point is calculated as the mean of raw scores. Then the mean SWB-set-point-range is calculated as $\mathrm{x} 4$ (w-pSD mean), comprising two w-pSD means on each side of the mean set-point.

This procedure differs slightly from that used in Study1. In the earlier study, the mean SWB-set-point-range was calculated using the average w-pSD means of categories within the range of set-points. The calculation for Study2 takes a more refined approach. It uses the means of all the individual w-pSDs within the range of set-points. The mean SWB-set-pointrange can be confirmed if it approximates that in Study1.

In summary, confirmation of set-points and the mean SWB-set-point-ranges, for GLS2 and HPMood, involves the following steps:

1. Finding the 5-point categories with the lowest w-pSD means for both variables. These categories provide the best estimates of the range of set-points.

2. Finding whether the personal set-points, within the range of set-points, are normally distributed for both variables.

3. Finding whether the mean SWB-set-point-range approximates 19 points.

\section{Results}

Data cleaning and iterative data-stripping analyses were conducted separately for GLS2 and HPMood. Data cleaning was conducted using SPSS version 22. Analyses were performed using STATA version 12.

The initial number of respondents, each of whom supplied between 5 and 10 scores on GLS2 and HPMood, was 1,125 and 950 respectively (see Appendix Table 3). This provides a total of 7,674 and 6,341 scores (see Appendix Tables 4 and 5). Each of these datasets was then subjected to the systematic process of data-stripping, as described in the method.

The complete elimination of outliers for GLS2 and HPMood was achieved over 5 and 6 iterations, respectively (see Appendix Tables 6 and 7). This process eliminated a total of 1,201 (15.65\%) GLS2 and 1,115 (17.58\%) HPMood scores. At the end of this process, a total 
of 40 GLS2 and 57 HPMood respondents was lost due to the elimination of non-reliable residual scores (n-rRS) throughout the analysis (see Appendix Table 3).

The following Tables 8 and 9 show the means of raw scores (Columns 2 and 5) for GLS2 and HPMood in each category before and after data-stripping. In general, datastripping has had little effect on the category means, with most having changed by less than one percentage point. The two exceptions are the lowest (0-45) and the highest (95.1-100) categories where HPMood has increased by 4.18 and 2.69 points, respectively (Columns 2 and 5 in Table 9). These lowest and highest categories are retained in subsequent calculations shown below, however they are not used in the final estimation of set-points (see later Table 12). Thus, the proportional changes for both variables, in terms of category means used for the set-point estimations, have been equivalent.

Table 8 Mean GLS2 scores and w-pSD means and SDs of w-pSDs before and after datastripping

\begin{tabular}{|c|c|c|c|c|c|c|}
\hline \multirow[b]{2}{*}{$\begin{array}{l}\text { GLS2 } \\
\text { categories }\end{array}$} & \multicolumn{3}{|c|}{ Before the first iteration } & \multicolumn{3}{|c|}{ After the last iteration } \\
\hline & $\begin{array}{r}\text { Mean of } \\
\text { GLS2 } \\
\text { scores in } \\
\text { category }\end{array}$ & $\begin{array}{l}\text { w-pSD } \\
\text { mean in } \\
\text { category }\end{array}$ & $\begin{array}{l}\text { SD of w- } \\
\text { pSDs in } \\
\text { category }\end{array}$ & $\begin{array}{r}\text { Mean of } \\
\text { GLS2 } \\
\text { scores in } \\
\text { category }\end{array}$ & $\begin{array}{l}\text { w-pSD } \\
\text { means in } \\
\text { category }\end{array}$ & $\begin{array}{l}\text { SD of w- } \\
\text { pSDs in } \\
\text { category }\end{array}$ \\
\hline $0-45$ & 36.23 & 16.41 & 6.49 & 35.24 & 8.14 & 2.76 \\
\hline $45.1-50$ & 48.26 & 16.30 & 8.40 & 47.75 & 11.60 & 5.07 \\
\hline $50.1-55$ & 53.20 & 15.67 & 7.95 & 53.59 & 8.35 & 2.68 \\
\hline $55.1-60$ & 58.34 & 15.00 & 4.67 & 58.53 & 12.52 & 2.52 \\
\hline $60.1-65$ & 63.28 & 15.18 & 6.78 & 63.39 & 9.25 & 2.68 \\
\hline $65.1-70$ & 68.14 & 14.01 & 6.25 & 68.81 & 6.70 & 2.09 \\
\hline $70.1-75$ & 73.06 & 9.84 & 5.00 & 73.95 & 5.29 & 0.43 \\
\hline $75.1-80$ & 78.31 & 7.59 & 4.79 & 77.61 & 4.25 & 1.50 \\
\hline $80.1-85$ & 83.05 & 7.28 & 3.72 & 83.27 & 4.92 & 0.62 \\
\hline $85.1-90$ & 87.83 & 6.96 & 3.92 & 87.39 & 4.40 & 1.43 \\
\hline $90.1-95$ & 92.66 & 6.45 & 2.12 & 93.22 & 4.89 & 0.64 \\
\hline $95.1-100$ & 97.03 & 5.52 & 1.80 & 97.62 & 4.13 & 1.58 \\
\hline
\end{tabular}

Table 9 Mean HPMood scores and w-pSD means and SDs of w-pSDs before and after datastripping

\begin{tabular}{lrrrrrr}
\hline & \multicolumn{3}{c}{ Before the first iteration } & \multicolumn{2}{c}{ After the last iteration } \\
\cline { 2 - 7 } & $\begin{array}{r}\text { Mean of } \\
\text { HPM } \\
\text { scores in } \\
\text { category }\end{array}$ & $\begin{array}{r}\text { weans in } \\
\text { meategory }\end{array}$ & $\begin{array}{r}\text { SD of w- } \\
\text { pSDs in } \\
\text { category }\end{array}$ & $\begin{array}{r}\text { Mean of } \\
\text { HPM scores } \\
\text { in category }\end{array}$ & $\begin{array}{r}\text { w-pSD } \\
\text { means in } \\
\text { category }\end{array}$ & $\begin{array}{r}\text { SD of w- } \\
\text { pSDs in } \\
\text { category }\end{array}$ \\
\hline $0-45$ & 35.90 & 11.97 & 6.42 & 40.08 & 7.28 & 2.06 \\
$45.1-50$ & 47.75 & 13.59 & 6.51 & 47.88 & 9.81 & 3.87
\end{tabular}




\begin{tabular}{lrrrrrr}
$50.1-55$ & 53.01 & 12.33 & 4.58 & 53.20 & 7.52 & 2.17 \\
$55.1-60$ & 57.65 & 13.69 & 5.16 & 57.92 & 9.51 & 2.06 \\
$60.1-65$ & 62.55 & 12.45 & 5.39 & 62.79 & 8.73 & 2.92 \\
$65.1-70$ & 67.95 & 9.98 & 4.94 & 67.98 & 6.21 & 2.05 \\
$70.1-75$ & 72.87 & 9.24 & 4.13 & 73.25 & 5.33 & 1.40 \\
$75.1-80$ & 77.76 & 7.86 & 4.22 & 78.10 & 4.45 & 1.48 \\
$80.1-85$ & 82.61 & 7.06 & 3.79 & 83.07 & 4.12 & 1.20 \\
$85.1-90$ & 87.37 & 5.74 & 2.98 & 87.22 & 3.66 & 1.10 \\
$90.1-95$ & 92.76 & 6.29 & 2.49 & 92.83 & 4.86 & 1.32 \\
$95.1-100$ & 97.31 & 3.91 & 1.86 & 100.00 & 0.00 & 0.00 \\
\hline
\end{tabular}

Tables 8 and 9 also show the mean category variances ' $w$-pSD means in category' both before (column 3) and after (column 6) data-stripping, while columns 4 and 7 show the 'SDs of w-pSDs' in each category. These are summary statistics for the variance within each category, where the w-pSDs of individuals are used as data to create a SD of w-pSDs. The key categories for comparative purposes are the seven categories lying between 60.1 points and 95 points. These categories are considered for the calculation of set-points (see later). The percentage reduction in the 'SDs of w-pSDs' due to data stripping, within the 7 categories from 60.1 to 95 points, is as follows:

GLS2: $\quad 60.47,66.56,91.40,68.68,83.38,63.52,69.81 \%$;

HPMood: $\quad 45.82,58.50,66.10,64.93,68.34,63.09,46.99 \%$.

These values show the reduction of variance following data-stripping within those categories lying between 60.1 and 95 points. This variance, calculated from the mean of individual w-pSDs within each GLS2 and HPMood category, has been reduced between 45.82 and 91.40 percent. The lowest reduction for both GLS2 and HPMood was in the 60.1 65 point category, $60.47 \%$ and $45.82 \%$ respectively. The highest reduction for GLS2 occurred in the 70.1 - 75 point category $(91.40 \%)$ and for HPMood in the $80.1-85$ point category $(68.34 \%)$. Overall, GLS2 categories show greater reduction in variance than HPMood categories following data-stripping.

Finally, following data-stripping, $84.1 \%$ of GLS2 respondents and 86.3\% of HPMood respondents lie between 60.1 and 95 points (see Appendix Table 3). Outside this range, the proportions of people in GLS2 and HPMood categories are: $<60.1=10.1 \%$ and $11.4 \%$; and $>95.1=5.8 \%$ and $2.5 \%$, respectively. These values are comparable.

\subsection{Testing hypothesis 1 that:}

GLS2 and HPMood set-points will lie between 70.1 and 90 points.

This hypothesis has been tested using the results of the final data-stripping (Tables 8 and 9). These have been used to determine, for each variable, a cluster of categories showing the lowest-level w-pSD means. The comparative GLS2 and GLS1 results are shown in Figure 1 . 
A visual analysis shows the GLS2 categories between 70.1 and 90 points to have consistently low w-pSD means after data-stripping. These values are remarkably similar to GLS1. Within this 70.1 - 90 point range, w-pSD means between adjacent GLS2 categories vary by a maximum of 1.04 points (category $70.1-75$ vs $75.1-80: 5.29$ minus $4.25=1.04$ ). This compares to a maximum of 0.58 points in GLS1.

\section{INSERT FIGURE 1 HERE:}

The equivalent results for HPMood are shown in Figure 2. Here, w-pSD means within the 70.1 - 90 point range are less consistent than for GLS2, varying by a maximum of 1.67 points (category $70.1-75$ vs $85.1-90: 5.33$ minus $3.66=1.67$ ). Contributing to these larger variations is the unusually low w-pSD mean in the $85.1-90$ point category $(\mathrm{w}-\mathrm{pSD}$ mean $=$ 3.66).

\section{INSERT FIGURE 2 HERE:}

In the second step of this analysis, the $\mathrm{w}-\mathrm{pSD}$ means across all of the categories are compared using ANOVA. Both $F$ statistics are significant: $F_{\mathrm{GLS} 2}=(11,1074), 151.81, \mathrm{p}=.000$ and $\mathrm{F}_{\text {HPMood }}=(11,881), 94.32, \mathrm{p}=.000$. The post hoc analysis was conducted using the Dunnett's T3 post hoc criterion for significance. The results of this analysis are presented in Table 10 below.

Table 10 Significant differences in w-pSDs between categories

\begin{tabular}{lll}
\hline Categories & $\begin{array}{l}\text { Significant differences } \\
\text { between categories for } \\
\text { GLS2 (\#) }\end{array}$ & $\begin{array}{l}\text { Significant differences } \\
\text { between categories for } \\
\text { HPMood } \\
(\#)\end{array}$ \\
(\#) & $1<4$ & \\
\hline 1. $0-45$ & & $3<4$ \\
2. $45.1-50$ & $3<4$ & \\
3. 50.1-55 & & \\
4. 55.1-60 & $5<4$ & $6<2,4,5$ \\
5. 60.1-65 & $6<4,5$ & $7<2-5$ \\
6. 65.1-70 & $7<1,2,4-6$ & $9<1-7$ \\
7. $70.1-75$ & $8<1-7,9,11$ & $10<1-8,11$ \\
8. $75.1-80$ & $9<1-7$ & $11<1-6$ \\
9. $80.1-85$ & $10<1-7,9,11$ & $12<1-11$ \\
10. $85.1-90$ & $11<1-7$ & \\
11. 90.1-95 & $12<1-7,9,11$ & \\
12. 95.1-100 & & \\
\hline
\end{tabular}

Table 10 summarizes significant differences in w-pSD means between categories. Column 1 shows all categories numbered from 1 to 12. The Columns 2 and 3 show significant differences between categories for GLS2 and HPMood. The values that are compared in these columns refer to the order numbers of categories in Column 1. Thus, for GLS2, category 1 ('0-45') has significantly lower w-pSD means than category 4 ('55.1-60'). 
Table 10 shows that categories with significantly smaller w-pSD means generally lie above 65 points, as expected. Unexpectedly, significantly lower w-pSD means in categories above 90 are also notable. However, the w-pSD mean of zero in the 95.1-100 HPMood category (see Figure 2) makes the comparisons with this category unreliable, as do also the smaller sample sizes (see Appendix Table 3).

In an attempt to compensate for the low sample sizes and zero variance, the six categories below 70.1 points were merged into two (' $0-60$ ' and ' $60.1-70$ '), and the two categories above 90 points were merged into a single category ('90.1 - 100'). The resulting sample sizes in compressed categories are presented in the Appendix Table 11.

The iterative data-stripping process was repeated using the newly created 7 categories: three compressed (0-60, 60.1-70 and 90.1-100) and four non-compressed (70.1$75,75.1-80,80.1-85,85.1-90)$. The raw scores are distributed based on their means belonging to the 7 categories. However, after merging and data-stripping, the number of scores in the 90.1 - 100 point category for HPMood still comprised less than 100. Furthermore, the wpSDs with a value of zero, reduced the reliability of the estimated true variance for people in that category. Therefore, it was decided to omit the 90.1 - 100 HPMood category from further analysis. For consistency, the same was done for GLS2. The results after this excision are presented in Figure 3.

\section{INSERT FIGURE 3 HERE:}

In Figure 3, the w-pSD means in the four GLS2 and HPMood categories within the 70.1 - 90 point range have remained almost identical to those in the uncompressed categories (Figure 2). This is because the width of these categories and the membership of people in those categories did not change. However, the w-pSD means in the compressed categories are different from the w-pSD means of the original categories. This is because the membership of people in those categories did change, as determined by the wider normative ranges.

Based on Figure 3 and using the criterion of the smallest and most consistent w-pSD means to identify set-points, the range of GLS2 set-points appears to lie between 70.1 and 90 points. There is, however, a point of ambiguity concerning the interface between the 60.1-70 and 70.1-75 categories for HPMood. While these two values for GLS2 are separated by 3.69 points, for HPMood they are separated by just 0.22 points. This indicates that, for HPMood only, the range of set-points could extend down to include the 60.1-70 point category.

Due to this lack of agreement between GLS2 and HPMood categories regarding the lower end of the range of set-points, the results from Study1 and Study2 have been examined more closely to see which range seems to offer the best estimate of commonality.

The new analysis is shown in Table 12. The first part of the table, Section 1 'People in 5-point categories' presents the Ns after data-stripping for each of the three variables within the maximum range of possible interest for both studies, from 60.1 to 95 points. It also includes the sample proportions in parentheses. Based on the results shown in Figure 2 and 3, this is considered as the widest possible range in which set-points are likely to be distributed.

For consistency, this 60.1 to 95 point range is sub-divided into seven 5-point categories with the values for each category represented in a column. Section 1 in Table 12 shows that the proportions of the sample within each cell are comparable between the three 
variables (GLS1, GLS2, and HPMood). It also shows that, for GLS2 and HPMood, the Ns in the three extreme ranges $(60.1-65,65.1-70$ and $90.1-95)$ are too low $(<100)$ to have confidence that the w-pSD mean estimates are reliable.

Table 12 Estimation of the range of set-points based on GLS1, GLS2 and HPMood after data-stripping

\section{Section 1}

People in 5-point categories

\begin{tabular}{|c|c|c|c|c|c|c|c|c|}
\hline \multirow{4}{*}{$\begin{array}{l}\text { People } \\
\text { N } \\
(\%)\end{array}$} & ories & $60.1-65$ & $65.1-70$ & $70.1-75$ & $75.1-80$ & $80.1-85$ & $85.1-90$ & $90.1-95$ \\
\hline & GLS1 & $\begin{array}{l}241 \\
(3.30)\end{array}$ & $\begin{array}{l}493 \\
(6.76)\end{array}$ & $\begin{array}{l}1,031 \\
(14.13)\end{array}$ & $\begin{array}{l}1,575 \\
(21.59)\end{array}$ & $\begin{array}{l}1,417 \\
(19.42)\end{array}$ & $\begin{array}{l}1,065 \\
(14.60)\end{array}$ & $\begin{array}{l}704 \\
(9.65)\end{array}$ \\
\hline & GLS2 & $\begin{array}{l}45 \\
(4.14)\end{array}$ & $\begin{array}{l}63 \\
(5.80)\end{array}$ & $\begin{array}{l}142 \\
(13.08)\end{array}$ & $\begin{array}{l}252 \\
(23.20)\end{array}$ & $\begin{array}{l}186 \\
(17.13)\end{array}$ & $\begin{array}{l}158 \\
(14.55)\end{array}$ & $\begin{array}{l}68 \\
(6.26)\end{array}$ \\
\hline & HPMood & $\begin{array}{l}50 \\
(5.60)\end{array}$ & $\begin{array}{l}68 \\
(7.61)\end{array}$ & $\begin{array}{l}124 \\
(13.89)\end{array}$ & $\begin{array}{l}191 \\
(21.39)\end{array}$ & $\begin{array}{l}150 \\
(16.80)\end{array}$ & $\begin{array}{l}131 \\
(14.67)\end{array}$ & $\begin{array}{l}56 \\
(6.27) \\
\end{array}$ \\
\hline
\end{tabular}

Section 2

w-pSD means in 5-point categories

\begin{tabular}{lllllllll}
\hline Categories & & $60.1-65$ & $65.1-70$ & $70.1-75$ & $75.1-80$ & $80.1-85$ & $85.1-90$ & $90.1-95$ \\
\hline \multirow{4}{*}{$\begin{array}{l}\text { w-pSD } \\
\text { means }\end{array}$} & GLS1 & 9.32 & 6.40 & 5.04 & 4.46 & 4.84 & 4.59 & 6.91 \\
& GLS2 & 9.25 & 6.70 & 5.29 & 4.25 & 4.92 & 4.40 & 4.89 \\
\cline { 2 - 9 } & HPMood & 8.73 & 6.21 & 5.33 & 4.45 & 4.12 & 3.66 & 4.86 \\
\hline & All & \multirow{2}{*}{6.10} & 6.44 & 5.22 & 4.39 & 4.63 & 4.22 & \multirow{2}{*}{5.55} \\
\hline
\end{tabular}

The separation of w-pSD means between categories

\begin{tabular}{|c|c|c|c|c|c|c|c|}
\hline Categories & & $\begin{array}{l}\text { Interface } 1 \\
(60.1-65- \\
65.1-70) \\
\end{array}$ & $\begin{array}{l}\text { Interface } 2 \\
(65.1-70- \\
70.1-75)\end{array}$ & $\begin{array}{l}\text { Interface } 3 \\
(70.1-75 \text { - } \\
75.1-80) \\
\end{array}$ & $\begin{array}{c}\text { Interface } 4 \\
(75.1-80- \\
80.1-85) \\
\end{array}$ & $\begin{array}{l}\text { Interface } 5 \\
(80.1-85- \\
85.1-90) \\
\end{array}$ & $\begin{array}{l}\text { Interface } 6 \\
(85.1-90- \\
90.1-95) \\
\end{array}$ \\
\hline \multirow{3}{*}{$\begin{array}{l}\text { Degree of } \\
\text { separation } \\
\text { between w- } \\
\text { pSD means }\end{array}$} & GLS1 & 2.92 & 1.36 & 0.58 & 0.38 & 0.25 & 2.32 \\
\hline & GLS2 & 2.55 & 1.41 & 1.04 & 0.67 & 0.52 & 0.49 \\
\hline & HPMood & 2.52 & 0.88 & 0.88 & 0.33 & 0.46 & 2.32 \\
\hline $\begin{array}{l}\text { Mean } \\
\text { degree of } \\
\text { separation }\end{array}$ & $\begin{array}{l}\text { All } \\
\text { variables }\end{array}$ & 2.66 & 1.22 & 0.83 & 0.24 & 0.41 & 1.34 \\
\hline
\end{tabular}

w-pSD means in the estimated range of set-points

(Maximum w-pSD mean minus Minimum w-pSD mean within each range)

\begin{tabular}{lllll}
\hline \multicolumn{2}{l}{ Range of set-points } & $70.1-90$ & $75.1-95$ & $75.1-90$ \\
\hline \multirow{2}{*}{ w-pSD } & GLS1 & 0.58 & 2.45 & 0.38 \\
mean (Max- & GLS2 & 1.04 & 0.67 & 0.67 \\
Min) & HPMood & 1.67 & 1.20 & 0.79 \\
\hline \multicolumn{4}{c}{ Note: GLS1 = GLS in Study 1; GLS2 = GLS in Study 2; HPMood = HPMood in Study 2; }
\end{tabular}

Section 2 'w-pSD means in 5-point categories' of Table 12 shows the corresponding w-pSD means for each cell involving each of the three variables as GLS1, GLS2 and HPMood. The $21 \mathrm{w}-\mathrm{pSD}$ means all lie between 9.32 points (GLS1: $60.1-65$ ) and 3.66 points (HPMood: 85.1 - 90), a range of 5.66 points. The last row in Section 2 shows the group wpSD mean for all three variables within each category. These range from the highest (w-pSD mean $=9.10)$ in the $60.1-65$ point category and the lowest $(\mathrm{w}-\mathrm{pSD}$ mean $=4.22)$ in the 85.1 -90 point category. When the group w-pSD means are compared, they are most consistent in 
the three categories between 75.1 and 90 points. Within this range w-pSD means are separated by a maximum of 0.41 points (category $80.1-85$ vs $85.1-90: 4.63$ minus $4.22=$ 0.41). Thus, based on this approach, the range of $75.1-90$ points appears as the best choice as an estimate of the range of set-points.

To test the robustness of this approach in estimating the range of set-points, Section 3 of Table 12 was prepared as 'The separation of w-pSD means between Categories'. This section shows, the degree of separation between the w-pSD means for each pair of adjacent categories (eg. 60.1 - 65 and 65.1 - 70) for each of the three variables. The point at which two adjacent categories meet is named 'Interface'. The final row in this section shows the mean degree of separation in w-pSD means, across all three variables, for each category interface.

The analysis to be applied to this table section is twofold. First, variables with the maximum and minimum separations in w-pSD means across adjacent categories are identified for each interface. Second, the maximum and minimum values at one interface are compared with the maximum and minimum values at the next highest interface. The rationale for this approach is that the analysis is working towards the determination of a common range of set-points that applies across all three variables. This can be achieved by identifying the lowest and the highest interface with consistently low degree of separation across all three variables.

Following the above strategy, the first set of comparisons are made in order to determine the most probable upper-end of the range of set-points. This involves a comparison between the maximum and minimum values comprising the highest interface (Interface 6) with the three corresponding values comprising the second-highest interface (Interface 5). Thus, the values at Interface 6 are: $\operatorname{Max}=2.32$ and $\operatorname{Min}=0.49$ and for Interface 5: Max = 0.52 and $\mathrm{Min}=0.25$. Because Interface 5 shows much greater consistency in w-pSD means between the three variables, we conclude that the $85.1-90$ point category represents the upper end of the range of set-points.

At the lower end of the range the determination of the break between categories is less clear. When the lowest interface (Interface 1) is compared with the next highest interface (Interface 2), the results are: Interface 1: $\operatorname{Max}=2.92$ and $\operatorname{Min}=2.52$, and for Interface 2: $\operatorname{Max}=1.41$ and $\mathrm{Min}=0.88$. The degrees of separation at Interface 2 are both lower and more consistent than those at Interface 1 . Thus from this comparison, Interface 2 presents clearly as a better choice. However, the degrees of separation across this interface are considerably higher than those at the upper end of the range. Therefore, it was decided to also compare the values in Interface 2 with the values across the next highest interface (Interface 3 ).

The maximum and minimum distinctions across Interface 3 are: $\mathrm{Max}=1.04$ and Min $=0.58$, respectively. These values remain substantially higher than the degrees of separation used to determine the top of the range of set-points ( $\operatorname{Max}=0.52$; Min $=0.25$ ). Thus, this estimate of the lowest limit of the range of set-points cannot be regarded with such confidence.

The final row of Section 3 shows the combined data from the three variables ("Mean degree of separation"). Here, the upper-end of the range of set-points seems clearly marked by Interface 5 , and the lower by interface 4 . Therefore, based on this comparison, the range of set-points would lie between 75.1 and 90 points. 
In a final effort to settle on the best lower range limit, Section 4 ' $w$-pSD means in estimated range of set-points of Table 12 has been prepared. Section 4 shows the discrepancy between the maximum and the minimum w-pSD means within each of the proposed range of set-points. The calculations are based on w-pSD means in Section 2 of Table 12. The estimated ranges are:

70.1 - 90: This 20-point range is non-optimal for any of the variables. Even for GLS1, where this was the chosen range of set-points for Study1, the w-pSD mean value of .58 is trumped by .38 in the third column.

75.1 - 95: This 20-point range is only equal-optimal (.67) with 75.1 - 90 for GLS2.

$75.1-90$ : This is the optimal range (showing the lowest set of w-pSD means) for all three variables.

It is concluded in relation to hypothesis 1, 'that GLS2 and HPMood set-points will lie between 70.1 and 90 points' is only supported for the upper marker. The lower marker appears to be at 75 points.

\subsection{Testing hypothesis 2 that:}

GLS2 and HPMood set-points will be normally distributed around the mean set-point for the sample.

Within the range of set-points, estimated to lie between 75.1 and 90 percentage points, the mean set-point for GLS2 is 82.07 points and for HPMood 82.19 points. The SD for GLS2 is calculated as 4.23 and for HPMood as 3.99 points. From this, the confidence intervals were calculated for both GLS2 and HPMood, using 3 SDs around the mean set-point for the sample. The resulting confidence intervals for GLS2 are 69.4 to 94.8 and for HPMood are 70.2 to 94.2 . These confidence intervals are comparable between GLS2 and HPMood. The set-point distributions, for both GLS2 and HPMood, are presented in Figure 4 and 5 respectively. The percentages denoting the relative frequency of scores falling within each of the designated SD ranges sum to $100 \%$ for each distribution. The respective proportions of individual means lying below, within and above 3 SDs are $17 \%, 76 \%$ and $7 \%$ for GLS2, and $24 \%, 72 \%$ and $4 \%$ for HPMood. These proportions are also comparable.

\section{INSERT FIGURE 4 HERE:}

\section{INSERT FIGURE 5 HERE:}

From Figures 4 and 5, the distribution of GLS2 and HPMood set-points within each $99.7 \%$ confidence interval appear to be approximately normal. However, there is a tendency for more scores to fall below the mean than to fall above. The reason for this will now be examined.

Taking first the GLS2 distribution (Figure 4), the proportion of scores falling below and above the mean is 58:42. This non-normality is most pronounced in the -2SD group, which contains a higher proportion of responses than normality would predict. The $99.7 \%$ confidence interval also extends asymmetrically outside the set-point distribution of $75.1-90$ points. At the lower end it extends down to 69.38 (-5.62 points) while the upper end it extends up to 94.76 ( +4.76 points). 
A similar influence can be seen in the distribution of HPMood (Figure 5). The proportion of scores falling below and above the mean is 55:45, which is similar to GLS2. The non-normality is most pronounced in the -2SD and -3SD groups. However the range extension is much more symmetrical than for GLS2. The $99.7 \%$ confidence interval extends down to 70.22 ( -4.78 points) and extends up to 94.16 (+4.16 points).

In summary, the hypothesis is supported in that the set-points for both GLS2 and HPMood are approximately normally distributed. However, both variables also show a tendency for this distribution to extend further below the mean.

\subsection{Testing the hypothesis 3 that:}

The mean SWB-set-point-range for both GLS2 and HPMood will be around 19 points.

Defined by (4xw-pSD mean), The SWB-set-point-range is the range within which measures of SWB are found for each person following data-stripping. From the estimated range of set-points of 75-90 points, the mean SWB-set-point-ranges for GLS2 and HPMood are 18.01 and 16.51 points, respectively. While both of these values are lower than the 19 points previously calculated for GLS1, the value for HPMood is 1.5 points lower than for GLS2.

In conclusion, due to the greater reliability and conceptual validity of the HPMood measure, the estimated value of 16.5 points will be considered as the best approximation of the average SWB-set-point-range for each person.

\section{Discussion}

This study (Study2) was designed to enhance the relevance of Subjective Wellbeing (SWB) to the formation of public policy. Essential to achieving this purpose is an understanding of the composition and properties of SWB. Such information is necessary to explain why the level of SWB rises and falls for both an individual and for the nation.

The dominant component of SWB is now understood to be mood affect, which is normally maintained under the influence of a homeostatic system (Cummins, 2016a). This conceptualization allows predictions to be made regarding aspects of public policy that pertain to the provision of resources and their likely influence on SWB. This will be elaborated later. First, however, it is necessary to have convincing evidence for the proposed homeostatic system that manages levels of SWB, and fundamental to this requirement is the existence of set-points (McEwen \& Wingfield, 2003; McGue, Bacon, \& Lykken, 1993; Williams \& Thompson, 1993).

While set-points have been validly demonstrated in Study1 (Cummins et al., 2014) there is a scientific need for reliability verification, using a different set of data. Providing such replication is the first aim of the study. The second aim is to test whether the distribution of set-points is normal. The third aim is to test whether the average range within which SWB values are found around each set-point is equivalent for all three variables being examined as: Study1 (General Life Satisfaction: GLS1) and Study2 (GLS2), and Homeostatically Protected Mood (HPMood) in Study2. 
In terms of verification, there are two key assumptions underpinning the demonstration of set-points. The first is that homeostatic processes operate over only a limited range of the entire $0-100$ point response scale. Within this limited range, homeostasis operates to maintain the SWB of each individual close to their set-point. Outside this range, homeostasis lacks the power to attract SWB close to set-point. The result is a wider spread of SWB values for people lying outside the limited homeostatic range.

The second assumption is statistical. This is that the power of homeostasis, to maintain SWB close to its set-point, can be determined through three stages of analysis. First, to use the SWB values for each person to calculate a mean and a within-person standard deviation (w-pSD). Second, to use two w-pSDs on each side of the mean ( $\mathrm{x} 4 \mathrm{w}-\mathrm{pSDs}$ ) to generate a range within which about $95 \%$ of that person's SWB values should fall. Third, to eliminate values lying outside this range because they are likely not under homeostatic control.

During the data analysis, this three-stage statistical process is repeated for each person until their $\mathrm{x} 4(\mathrm{w}-\mathrm{pSD})$ range contains all of their remaining scores. Then it is assumed, the smaller is this residual range, the more likely are the remaining SWB values to represent that person's set-point.

Using these assumptions and the iterative process of analysis described, the key findings are that a) the set-points for GLS (considering both GLS1 and GLS2) and HPMood in the Australian population appear to be distributed between 75 and 90 points, and b) the average set-point-range for each person, calculated as 4(w-pSD), is approximately 16.5 points for both GLS and HPMood. Overall, the results closely approximate those in Study1, but with a more restricted range of set-points and a narrower set-point-range for both variables.

Also notable is the high degree of congruence between the results using GLS2 and HPMood data. This was anticipated since the main constituent of GLS is HPMood (Blore et al., 2011; Davern et al., 2007; Tomyn \& Cummins, 2011), and HPMood is proposed to be the affective construct being protected by the SWB homeostatic system (Cummins, 2010). These results are therefore supportive of the general picture of SWB homeostasis that is being developed around the use of these variables.

However, despite this encouraging outcome, there are several aspects of the methodology and results that warrant thoughtful consideration. First among these is the art of defining the range of set-points within the sample.

Determining the range of set-points is a matter of careful judgement. In the absence of a strong criterion for this definition, the range in which set-points could reasonably exist, from 60.1 to 95.0 points (Cummins, 2003; Cummins et al., 2014) was divided into 7 intervals of 5-points each. This was done for all three variables as GLS1 from Study1, and GLS2 and HPMood from Study2. The w-pSD values were averaged within each interval, and then examined through the process described in relation to Table 12. The aim of this procedure was to determine the smallest range of w-pSD means that formed a consistent pattern between the three variables.

While the upper end of the range of set-points (85.1 to 90.0 points) was consistent between the three variables, the lower end of the range was harder to identify. Following careful examination it was decided that the lower end of the range determined from Study 1 
(70.1 points) is probably too low, and that a higher margin of 75.1 points was better indicated. Two observations pertain. First, it is remarkable to discover such close agreement between the results of both studies. Deciding between the two lower margins was a hard-call. Second, the uncertain precision of the lower margin of the range of set-points is likely contributed by the crude measurement instrument. The 0-10 response scale constitutes a 10 percentage point difference between adjacent numerical choices. Because of this factor alone, the more certain delineation of the lower end of the range of set-points may remain unresolved until more refined techniques of data acquisition or analysis are devised.

The second matter requiring consideration is the shape of the set-point distributions within the range of set-points. This shape is informed by the general agreement that SWB is a variable under strong genetic control (Lykken \& Tellegen, 1996; Røysamb, Harris, Magnus, Vitterso, \& Tambs, 2002; Stubbe, Posthuma, Boomsma, \& de Geus, 2005). Thus, since we have demonstrated that the major component of SWB is HPMood, it is expected that HPMood has the character of an individual difference between people. If this is so, then the set-point distributions should be normal. The distributions for GLS2 and HPMood are depicted in Figures 4 and 5 respectively. While both distributions show an approximately normal distribution, both also evidence a trend towards having more values below the mean than would be predicted by simple normality.

The explanation for this disparity may lie in a systematic error within the set-point determination procedure. The method of this determination, as described, is based on the assumption that data-stripping has removed emotional responses, leaving only responses that approximate the mood set-point for each person. While this assumption is likely reasonable in cases where the occasional emotional response is substantially different from set-point, emotional responses must come in varying levels of intensity. If an emotional response is too weak for it to be recognized as an outlier by data-stripping, it will remain as a contaminant. Moreover, such contamination is more likely to cause responses to be lower, rather than higher than set-point. This is due to the relative power of the restorative forces of homeostasis (Cummins et al., 2014). That is, while emotional responses above set-point are quickly negated through a combination of habituation and adaptation, emotional responses below setpoint may be longer-lasting due to a chronic stressor which is persistently challenging homeostasis. This is consistent with recent findings that people are more likely to experience a chronic reduction than a chronic elevation in SWB (Anglim, Weinberg, \& Cummins, 2015). Thus, perhaps, this source of systematic error is the reason for the slightly higher proportion of values below the set-point mean.

The final concern to be discussed is that, while Study1 estimated the mean SWB-setpoint-range for GLS1 to be 19 points, this study has found even lower values as 18.01 and 16.51 points for GLS2 and HPMood respectively. A possible reason for these lower average values may be due to a methodological difference. Whereas in Sudy1 the outliers were removed together at the end of the last iteration, in Study2 the outliers were removed after each iteration of data-stripping. This latter procedure is likely to have resulted in smaller residual ranges at each step of the iteration, thereby yielding a smaller final SWB-set-pointrange. It is also notable that the SWB-set-point-range for HPMood is lower than for GLS2. This increased sensitivity is to be expected since HPMood is proposed to be the fundamental component of SWB which drives its stability (Anglim et al., 2015).

\subsection{Limitations and Future Research}


The major limitation of this study is that the magnitude of the range of set-points and the SWB-set-point-ranges is clearly overestimated for both HPMood and GLS2. This is because the method does not eliminate all outliers from the data. In future studies, more outliers could be controlled by asking participants whether, and to what extent, anything was causing them to feel happier or sadder than normal at the time of SWB measurement. This procedure would aid the elimination of outliers in the form of subtle emotional responses that cannot be detected through the process of data-stripping alone. The remaining data would likely show a narrower w-pSD, together with a narrower and more normal distribution of setpoints for both GLS2 and HPMood.

A second limitation is that this replication used another data set from the Australian population. If, as we suspect, the demonstrated character of set-points represents a basic genetic determination, then this character should be invariant across the human species. If this is so, then demographic differences in wealth or age, and the ethnic origin of the data should not influence the 75 to 90 percentage point range of set-points we have described.

\subsection{Conclusion}

The potential usefulness of SWB for public policy has been advanced by confirming the reliable demonstration of set-points. These results confirm that GLS and HPMood setpoints within a general population sample are approximately normally distributed between 75 and 90 points, and that the mean personal SWB-set-point-range is around 16.5 points. In other words, on a 0-10 response scale, most people's GLS and HPMood scores normally vary by less than one response-point on either side of their mean. This finding confirms the heart of homeostasis theory, that for most people most of the time, their homeostatic system is able to control emotion challenges. More importantly, it enhances understanding of the relationship between SWB and societal resources, such as money, which can be influenced by public policy. This homeostatic relationship is not linear (Cummins, 2016a), which helps to explain why SWB is normally so stable compared to other social indicators, why any resource beyond a certain level is not associated with yet higher SWB, and why SWB below a threshold of 50 points signals an enhanced risk of depression (Cummins, 2010). It is timely for SWB to be routinely employed as a social indicator in addition to wealth. 
Acknowledgement

We are deeply grateful for the selfless and collegial assistance provided to us by the anonymous reviewers. The final product is a tribute to their true academic spirit and shared intellect. We also gratefully acknowledge our industry partner, Australian Unity, whose staunch support over many years of data collection made this demonstration of set-points possible.

\section{APPENDICES}

Table 3 Number and proportion of people in each GLS2 and HPMood category before and after data-stripping

\begin{tabular}{lllllllll}
\hline & \multicolumn{3}{c}{ GLS2 distribution } & \multicolumn{3}{c}{ HPMood distribution } \\
\cline { 2 - 9 } & $\begin{array}{l}\text { Before } \\
\text { data-stripping }\end{array}$ & $\begin{array}{l}\text { After } \\
\text { data-stripping }\end{array}$ & \multicolumn{2}{l}{$\begin{array}{l}\text { Before } \\
\text { data-stripping }\end{array}$} & $\begin{array}{l}\text { After } \\
\text { data-stripping }\end{array}$ \\
\cline { 2 - 9 } Categorie & $\mathrm{N}$ & $\%$ & $\mathrm{~N}$ & $\%$ & $\mathrm{~N}$ & $\%$ & $\mathrm{~N}$ & $\%$ \\
\hline $0-45$ & 31 & 2.8 & 30 & 2.8 & 26 & 2.7 & 21 & 2.4 \\
$45.1-50$ & 19 & 1.7 & 18 & 1.7 & 20 & 2.1 & 22 & 2.5 \\
$50.1-55$ & 25 & 2.2 & 15 & 1.4 & 31 & 3.3 & 22 & 2.5 \\
$55.1-60$ & 50 & 4.4 & 46 & 4.2 & 50 & 5.3 & 36 & 4.0 \\
$60.1-65$ & 68 & 6.0 & 45 & 4.1 & 58 & 6.1 & 50 & 5.6 \\
$65.1-70$ & 95 & 8.4 & 63 & 5.8 & 85 & 8.9 & 68 & 7.6 \\
$70.1-75$ & 149 & 13.2 & 142 & 13.1 & 157 & 16.5 & 124 & 13.9 \\
$75.1-80$ & 218 & 19.4 & 252 & 23.2 & 184 & 19.4 & 191 & 21.4 \\
$80.1-85$ & 175 & 15.6 & 186 & 17.1 & 138 & 14.5 & 150 & 16.8 \\
$85.1-90$ & 179 & 15.9 & 158 & 14.5 & 112 & 11.8 & 131 & 14.7 \\
$90.1-95$ & 75 & 6.7 & 68 & 6.3 & 60 & 6.3 & 56 & 6.3 \\
$95.1-100$ & 41 & 3.6 & 63 & 5.8 & 29 & 3.1 & 22 & 2.5 \\
\hline Total & 1,125 & \multicolumn{7}{c}{1,086} \\
\hline Note: $N=$ number of people in category; \% Proportion of people in category; & 893 & \\
\hline
\end{tabular}

Table 4 GLS2 scores excluded over 5 iterations

\begin{tabular}{|c|c|c|c|c|c|c|}
\hline $\begin{array}{l}\text { GLS2 } \\
\text { categories }\end{array}$ & $\begin{array}{l}\text { Scores } \\
\text { before } 1^{\text {st }} \\
\text { iteration } \\
\text { (N) }\end{array}$ & $\begin{array}{l}\text { Scores } \\
\text { below } \\
2 \mathrm{x} \mathrm{w}- \\
\text { pSD } \\
\text { mean in } \\
\text { category } \\
(\mathrm{N})\end{array}$ & $\begin{array}{l}\text { Scores } \\
\text { above } \\
2 \mathrm{x} \text { w- } \\
\text { pSD } \\
\text { mean in } \\
\text { category } \\
\text { (N) }\end{array}$ & $\begin{array}{l}\text { n-rRSs } \\
\text { (N) }\end{array}$ & $\begin{array}{l}\text { Total } \\
\text { scores } \\
\text { excluded } \\
\text { (N) }\end{array}$ & $\begin{array}{l}\text { Scores } \\
\text { remaining } \\
\text { after } 5^{\text {th }} \\
\text { iteration } \\
\text { (N) }\end{array}$ \\
\hline $0-45.0$ & 215 & 24 & 29 & 7 & 60 & 164 \\
\hline $45.1-50.0$ & 138 & 8 & 5 & 3 & 16 & 111 \\
\hline $50.1-55.0$ & 175 & 18 & 8 & 4 & 30 & 103 \\
\hline $55.1-60.0$ & 344 & 20 & 7 & 0 & 27 & 293 \\
\hline $60.1-65.0$ & 467 & 52 & 7 & 5 & 64 & 274 \\
\hline $65.1-70.0$ & 640 & 93 & 21 & 5 & 119 & 377 \\
\hline $70.1-75.0$ & 1,008 & 160 & 38 & 36 & 234 & 775 \\
\hline
\end{tabular}




\begin{tabular}{|c|c|c|c|c|c|c|}
\hline $75.1-80.0$ & 1,488 & 78 & 178 & 32 & 288 & 1,457 \\
\hline $80.1-85.0$ & 1,178 & 76 & 55 & 11 & 142 & 1,123 \\
\hline $85.1-90.0$ & 1,219 & 37 & 110 & 3 & 150 & 972 \\
\hline $90.1-95.0$ & 516 & 58 & 0 & 3 & 61 & 429 \\
\hline $95.1-100.0$ & 286 & 10 & 0 & 0 & 10 & 395 \\
\hline Total & 7,674 & 634 & 458 & 109 & 1,201 & 6,473 \\
\hline
\end{tabular}

Table 5 HPMood scores excluded over 6 iterations

\begin{tabular}{|c|c|c|c|c|c|c|}
\hline $\begin{array}{l}\text { HPMood } \\
\text { categories }\end{array}$ & $\begin{array}{l}\text { Scores } \\
\text { before } 1^{\text {st }} \\
\text { iteration }\end{array}$ & $\begin{array}{l}\text { Scores } \\
\text { below } \\
2 \mathrm{x} \mathrm{w}- \\
\mathrm{pSD} \\
\text { mean in } \\
\text { category } \\
\text { (N) }\end{array}$ & $\begin{array}{l}\text { Scores } \\
\text { above } 2 \mathrm{x} \\
\mathrm{w}-\mathrm{pSD} \\
\text { mean in } \\
\text { category } \\
\text { (N) }\end{array}$ & $\begin{array}{l}\text { n-rRSs } \\
(\mathrm{N})\end{array}$ & $\begin{array}{l}\text { Total } \\
\text { scores } \\
\text { excluded } \\
\text { (N) }\end{array}$ & $\begin{array}{l}\text { Scores } \\
\text { remaining } \\
\text { after } 6^{\text {th }} \\
\text { iteration } \\
\text { (N) }\end{array}$ \\
\hline $0-45.0$ & 175 & 34 & 13 & 25 & 72 & 119 \\
\hline $45.1-50.0$ & 135 & 8 & 6 & 0 & 14 & 135 \\
\hline $50.1-55.0$ & 198 & 13 & 15 & 0 & 28 & 125 \\
\hline $55.1-60.0$ & 339 & 22 & 6 & 0 & 28 & 228 \\
\hline $60.1-65.0$ & 397 & 31 & 6 & 0 & 37 & 320 \\
\hline $65.1-70.0$ & 543 & 58 & 15 & 7 & 80 & 398 \\
\hline $70.1-75.0$ & 1,060 & 132 & 29 & 23 & 184 & 732 \\
\hline $75.1-80.0$ & 1,254 & 141 & 56 & 24 & 221 & 1,121 \\
\hline $80.1-85.0$ & 912 & 109 & 32 & 19 & 160 & 835 \\
\hline $85.1-90.0$ & 753 & 48 & 57 & 15 & 120 & 766 \\
\hline $90.1-95.0$ & 382 & 19 & 0 & 0 & 19 & 339 \\
\hline $95.1-100.0$ & 193 & 109 & 0 & 43 & 152 & 108 \\
\hline Total & 6,341 & 724 & 235 & 156 & 1,115 & 5,226 \\
\hline
\end{tabular}


Table 6 Changes in GLS2 categories before and after each iteration

\begin{tabular}{|c|c|c|c|c|c|c|c|c|c|c|c|}
\hline \multirow[b]{3}{*}{ Categories } & \multicolumn{11}{|c|}{ GLS2 categories before and after each iteration } \\
\hline & \multicolumn{2}{|c|}{$1^{\text {st }}$ iteration } & \multicolumn{2}{|c|}{$2^{\text {nd }}$ iteration } & \multicolumn{2}{|c|}{$3^{\text {rd }}$ iteration } & \multicolumn{2}{|c|}{$4^{\text {th }}$ iteration } & \multicolumn{3}{|c|}{$5^{\text {th }}$ iteration } \\
\hline & $\begin{array}{l}\text { Scores } \\
\text { in } \\
\text { category } \\
\text { before } \\
1^{\text {st }} \\
\text { iteration }\end{array}$ & a1 & b1 & $\mathrm{a} 2$ & b2 & a3 & b3 & $\mathrm{a} 4$ & b4 & a5 & $\begin{array}{l}\text { Scores } \\
\text { in } \\
\text { category } \\
\text { after } 5^{\text {th }} \\
\text { iteration }\end{array}$ \\
\hline $0-45$ & 215 & -27 & -2 & -33 & 11 & 0 & 0 & 0 & 0 & 0 & 164 \\
\hline $45.1-50$ & 138 & -9 & -2 & -7 & -9 & 0 & 0 & 0 & 0 & 0 & 111 \\
\hline $50.1-55$ & 175 & -9 & -10 & -6 & -5 & -15 & -27 & 0 & 0 & 0 & 103 \\
\hline $55.1-60$ & 344 & -13 & -3 & -13 & -45 & -1 & 24 & 0 & 0 & 0 & 293 \\
\hline $60.1-65$ & 467 & -35 & -121 & -25 & -5 & -4 & -3 & 0 & 0 & 0 & 274 \\
\hline $65.1-70$ & 640 & -51 & -111 & -15 & 95 & -53 & -128 & 0 & 0 & 0 & 377 \\
\hline $70.1-75$ & 1,008 & -66 & -3 & -49 & 59 & -94 & -25 & -25 & -30 & 0 & 775 \\
\hline $75.1-80$ & 1,488 & -96 & 156 & -187 & -88 & -5 & 159 & 0 & 30 & 0 & 1,457 \\
\hline $80.1-85$ & 1,178 & -77 & 35 & -65 & 52 & 0 & 0 & 0 & 0 & 0 & 1,123 \\
\hline $85.1-90$ & 1,219 & -37 & -32 & -113 & -65 & 0 & 0 & 0 & 0 & 0 & 972 \\
\hline $90.1-95$ & 516 & -4 & 65 & -57 & -91 & 0 & 0 & 0 & 0 & 0 & 429 \\
\hline $95.1-100$ & 286 & -9 & 28 & -1 & 91 & 0 & 0 & 0 & 0 & 0 & 395 \\
\hline Total & 7,674 & -433 & & -571 & & -172 & & -25 & & 0 & 6,473 \\
\hline
\end{tabular}


Table 7 Changes in HPMood categories before and after each iteration

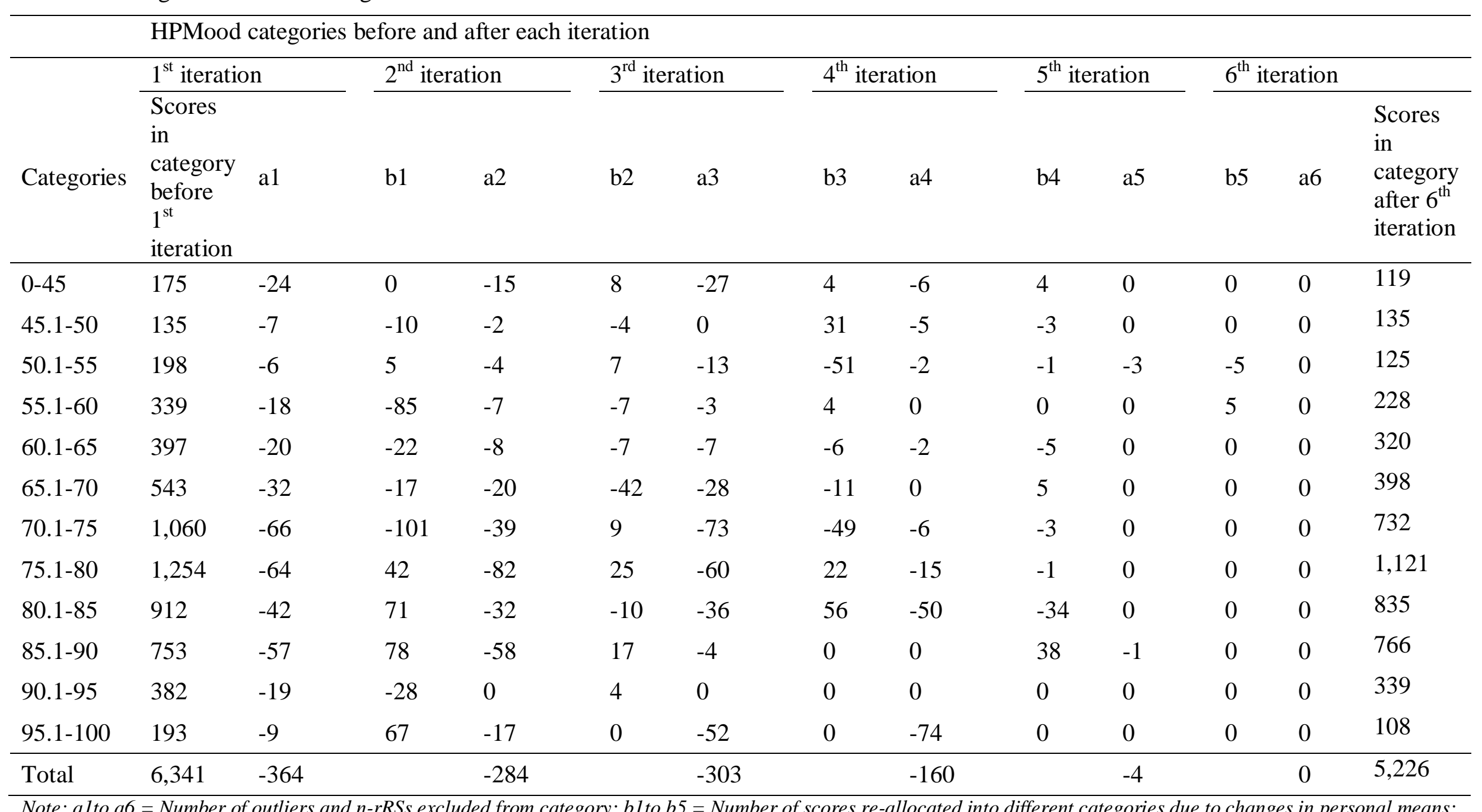


Table 11 Number and proportion of people in compressed GLS2 and HPMood categories before and after data-stripping

\begin{tabular}{|c|c|c|c|c|c|c|c|c|}
\hline \multirow[b]{3}{*}{ Categories } & \multicolumn{4}{|c|}{ GLS2 distribution } & \multicolumn{4}{|c|}{ HPMood distribution } \\
\hline & \multicolumn{2}{|c|}{$\begin{array}{l}\text { Before } \\
\text { data-stripping }\end{array}$} & \multicolumn{2}{|c|}{$\begin{array}{l}\text { After } \\
\text { data-stripping }\end{array}$} & \multicolumn{2}{|c|}{$\begin{array}{l}\text { Before } \\
\text { data-stripping }\end{array}$} & \multicolumn{2}{|c|}{$\begin{array}{l}\text { After } \\
\text { data-stripping }\end{array}$} \\
\hline & $\mathrm{N}$ & $\%$ & $\mathrm{~N}$ & $\%$ & $\mathrm{~N}$ & $\%$ & $\mathrm{~N}$ & $\%$ \\
\hline $0-60$ & 125 & 11.1 & 115 & 10.6 & 127 & 13.4 & 99 & 11.1 \\
\hline $60.1-70$ & 163 & 14.5 & 128 & 11.8 & 143 & 15.1 & 107 & 12.0 \\
\hline $70.1-75$ & 149 & 13.2 & 127 & 11.7 & 157 & 16.5 & 122 & 13.7 \\
\hline $75.1-80$ & 218 & 19.4 & 241 & 22.2 & 184 & 19.4 & 188 & 21.1 \\
\hline $80.1-85$ & 175 & 15.6 & 185 & 17.1 & 138 & 14.5 & 150 & 16.8 \\
\hline $85.1-90$ & 179 & 15.9 & 158 & 14.6 & 112 & 11.8 & 131 & 14.7 \\
\hline $90.1-100$ & 116 & 10.3 & 131 & 12.1 & 89 & 9.4 & 96 & 10.8 \\
\hline Total & 1,125 & & 1,08 & & 950 & & 893 & \\
\hline
\end{tabular}

Note: $N=$ number of people in category; \% = proportion of people in category; 


\section{References}

Anglim, J., Weinberg, M. K., \& Cummins, R. A. (2015). Bayesian hierarchical modeling of the temporal dynamics of subjective well-being: A 10 year longitudinal analysis. Journal of Research in Personality, 59, before publication. doi:http://dx.doi.org/10.1016/j.jrp.2015.08.003

Australian Bureau of Statistics. (2012). 2001.0 Census of Population and Housing: Basic Community Profile, 2011 Second Release. Canberra: ABS http://www.abs.gov.au/ausstats/abs@.nsf/mf/2001.0?OpenDocument.

Bauer, R. A. (1966). Social Indicators. Cambridge, MA: MIT Press.

Blore, J. D., Stokes, M. A., Mellor, D., Firth, L., \& Cummins, R. A. (2011). Comparing multiple discrepancies theory to affective models of subjective wellbeing. Social Indicators Research, 100(1), 1-16. doi:10.1007/s11205-010-9599-2

Branden, N. (1966). Emotions and values. The Objectivist, 5(5), 1-9.

Cummins, R. A. (2000). Personal income and subjective well-being: A review. Journal of Happiness Studies, 1(2), 133-158.

Cummins, R. A. (2003). Normative life satisfaction: Measurement issues and a homeostatic model. Social Indicators Research, 64(2), 225-256.

Cummins, R. A. (2010). Subjective wellbeing, homeostatically protected mood and depression: A synthesis. Journal of Happiness Studies, 11, 1-17. doi:10.1007/s10902009-9167-0

Cummins, R. A. (2016a). Subjective wellbeing as a social indicator. Social Indicators Research (in press).

Cummins, R. A. (2016b). The theory of subjective wellbeing homeostasis: A contribution to understanding life quality. In F. Maggino (Ed.), A Life Devoted to Quality of Life Festschrift in Honor of Alex C. Michalos (Vol. 60, pp. 61-79). Dordrecht, Netherlands: Springer.

Cummins, R. A., Li, L., Wooden, M., \& Stokes, M. (2014). A demonstration of set-points for subjective wellbeing. Journal of Happiness Studies, 15, 183-206.

doi:10.1007/s10902-013-9444-9

Davern, M., Cummins, R. A., \& Stokes, M. (2007). Subjective wellbeing as an affective/cognitive construct. Journal of Happiness Studies, 8(4), 429-449. doi:10.1007/s10902-007-9066-1

Diener, E., Kanazawa, S., Suh, E. M., \& Oishi, S. (2015). Why people are in a generally good mood. Personality and Social Psychology Review, 19 (3), 235-256.

Easterlin, R. A. (2005). Building a Better Theory of Well-Being Economics \& Happiness: Framing the Analysis. New York: Oxford University Press.

Forgas, J. P. (1991). Affect and social judgments: An introductory review. In J. P. Forgas (Ed.), Emotion and social judgments (pp. 3-30). Tarrytown, NY: Pergamon.

Frijda, N. H. (1986). The emotions. Cambridge: Cambridge University Press.

Halle, T. G. (2003). Emotional Development and Well-Being. In M. H. Bornstein, L. Davidson, C. Keyes, \& K. A. Moore (Eds.), Well-being: Positive development across the life course (pp. 125-138). Mahwah, NJ: Lawrence Erlbaum.

Hartmann, G. W. (1934). Personality traits associated with variations in happiness. Journal of Abnormal and Social Psychology, 29, 202-212.

Headey, B. (2010). The set point theory of well-being has serious flaws: On the eve of a scientific revolution. Social Indicators Research, 97(1), 7-21. doi:10.1007/s11205009-9559-x 
International Wellbeing Group. (2013). Personal Wellbeing Index Manual. 5th Edition. Retrieved from http://www.deakin.edu.au/research/acqol/instruments/wellbeingindex/pwi-a-english.pdf

Lai, L. C. H., \& Cummins, R. A. (2013). The contribution of job and partner satisfaction to the homeostatic defense of subjective wellbeing. Social Indicators Research, 111(1), 203-217. doi:10.1007/s11205-011-9991-6

Land, K. C. (1983). Social indicators. Annual Review of Sociology, 9, 1-26.

Land, K. C. (2015). The Human Development Index. In W. Glatzer, L. Camfield, V. Møller, \& M. Rojas (Eds.), Global Handbook of Quality of Life: Exploration of Well-Being of Nations and Continents (pp. 133-157). Dordrecht: Springer.

Land, K. C., \& Michalos, A. C. (2016). Fifty years after the social indiators movement: Has the promise been fulfilled? An Assessment and an Agenda for the Future. Social Indicators Research (in press).

Lazarus, R. S. (1991). Emotion and adaptation. New York: Oxford University Press.

Lykken, D., \& Tellegen, A. (1996). Happiness is a stochastic phenomenon. Psychological Science, 7(3), 186-189.

McEwen, B. S., \& Wingfield, J. C. (2003). The concept of allostasis in biology and biomedicine. Hormones and behavior, 43(1), 2-15.

McGue, M., Bacon, S., \& Lykken, D. T. (1993). Personality stability and change in early adulthood: A behavioral genetic analysis. Developmental Psychology, 29, 96-109. doi:10.1037/0012-1649.29.1.96

Meehl, P. E. (1990). Why summaries of research on psychological theories are often uninterpretable. Psychological Reports, 66, 195-244.

Røysamb, E., Harris, J. R., Magnus, P., Vitterso, J., \& Tambs, K. (2002). Subjective wellbeing. Sex-specific effects of genetic and environmental factors. Personality and Individual Differences, 32(2), 211-223.

Stubbe, J. H., Posthuma, D., Boomsma, D. I., \& de Geus, E. J. C. (2005). Heritability of life satisfaction in adults: A twin-family study. Psychological Medicine, 35(11), 15811588.

Tomyn, A. J. (2008). Subjective Wellbeing as an Affective Construct: Theory Development and Construction with Adolescents. Unpublished Doctoral Thesis. Deakin University, Melbourne. Retrieved from http://www.deakin.edu.au/research/acqol/theses/index.php

Tomyn, A. J., \& Cummins, R. A. (2011). Subjective wellbeing and homeostatically protected mood: Theory validation with adolescents. Journal of Happiness Studies, 12(5), 897914. doi:10.1007/s10902-010-9235-5

Watson, G. B. (1930). Happiness among adult students of education. Journal of Educational Psychology, 21, 79-109.

Watson, N., \& Wooden, M. (2012). The HILDA Survey: A Case Study in the Design and Development of a Successful Household Panel Study. Longitudinal and Life Course Studies, 3(3), 369-381.

Wessman, A. E., \& Ricks, D. F. (1966). Mood and personality. New York: Holt, Rinehart \& Winston.

Williams, D. E., \& Thompson, J. K. (1993). Biology and behavior: A set-point hypothesis of psychological functioning. Behavior Modification, 17, 43-57.

doi:10.1177/01454455930171004

\section{Confirmation of Subjective Wellbeing Set-points: Foundational for Subjective Social Indicators}


Figure 1 A comparison of the w-pSD means in GLS1 and GLS2 categories

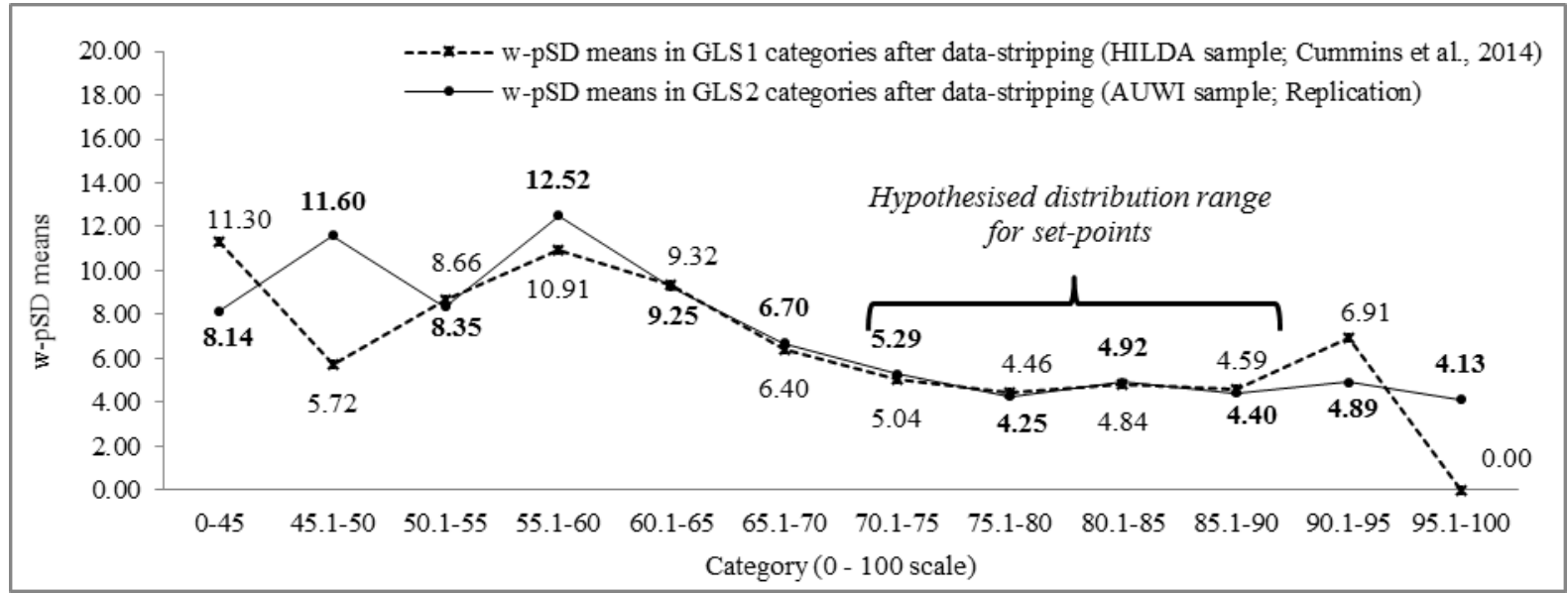

Figure 2 A comparison of the w-pSD means in GLS2 and HPMood categories

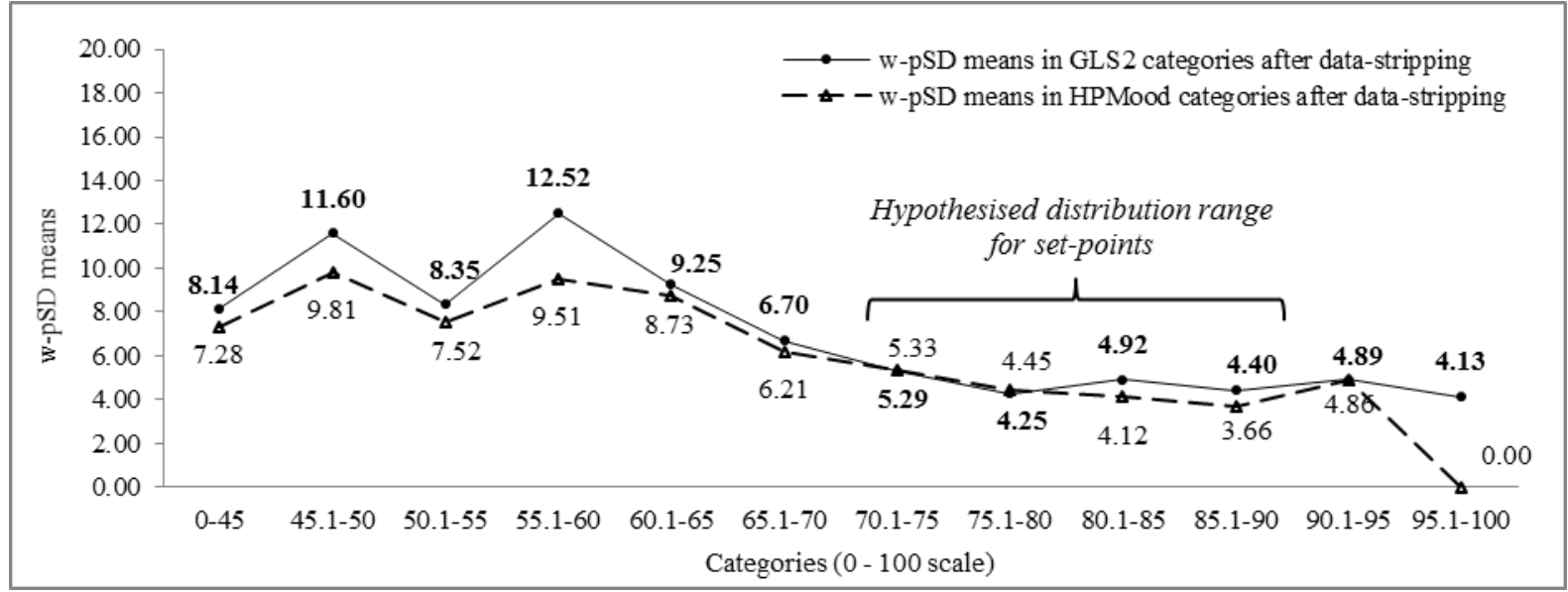

Figure 3 w-pSD means in six GLS2 and HPMood categories (0-90 points) after datastripping

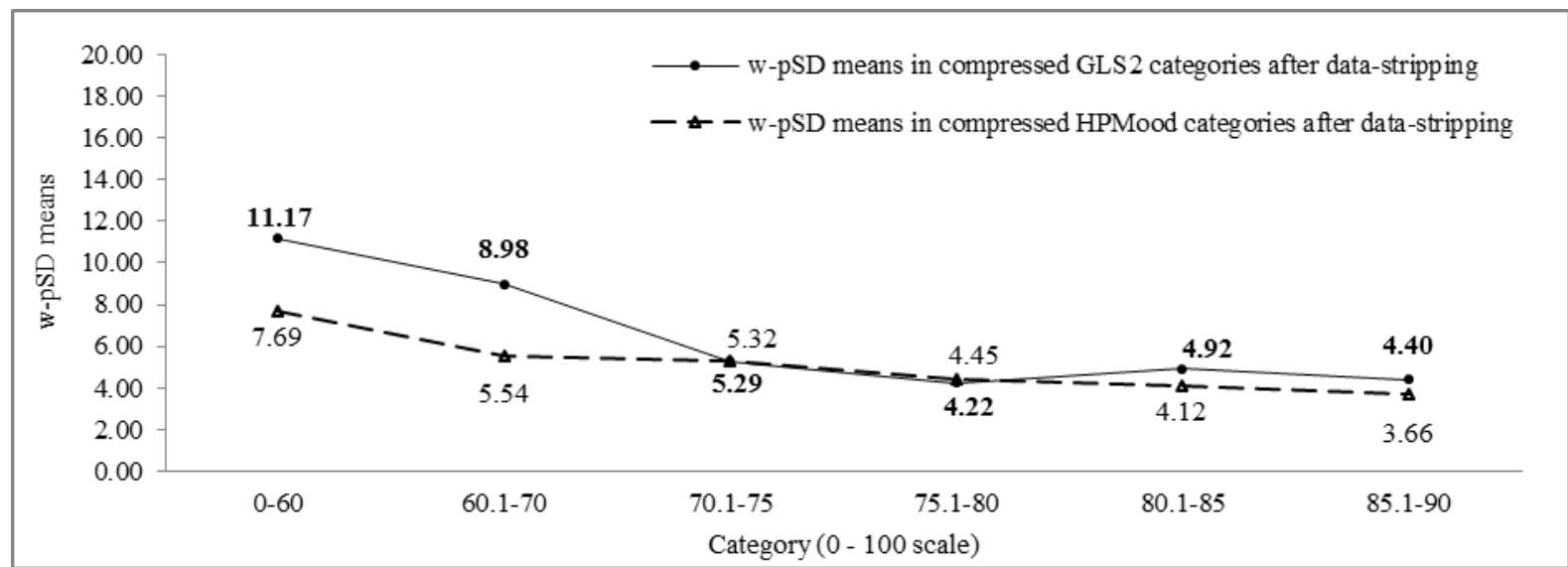

Figure 4 The distribution of GLS2 set-points 


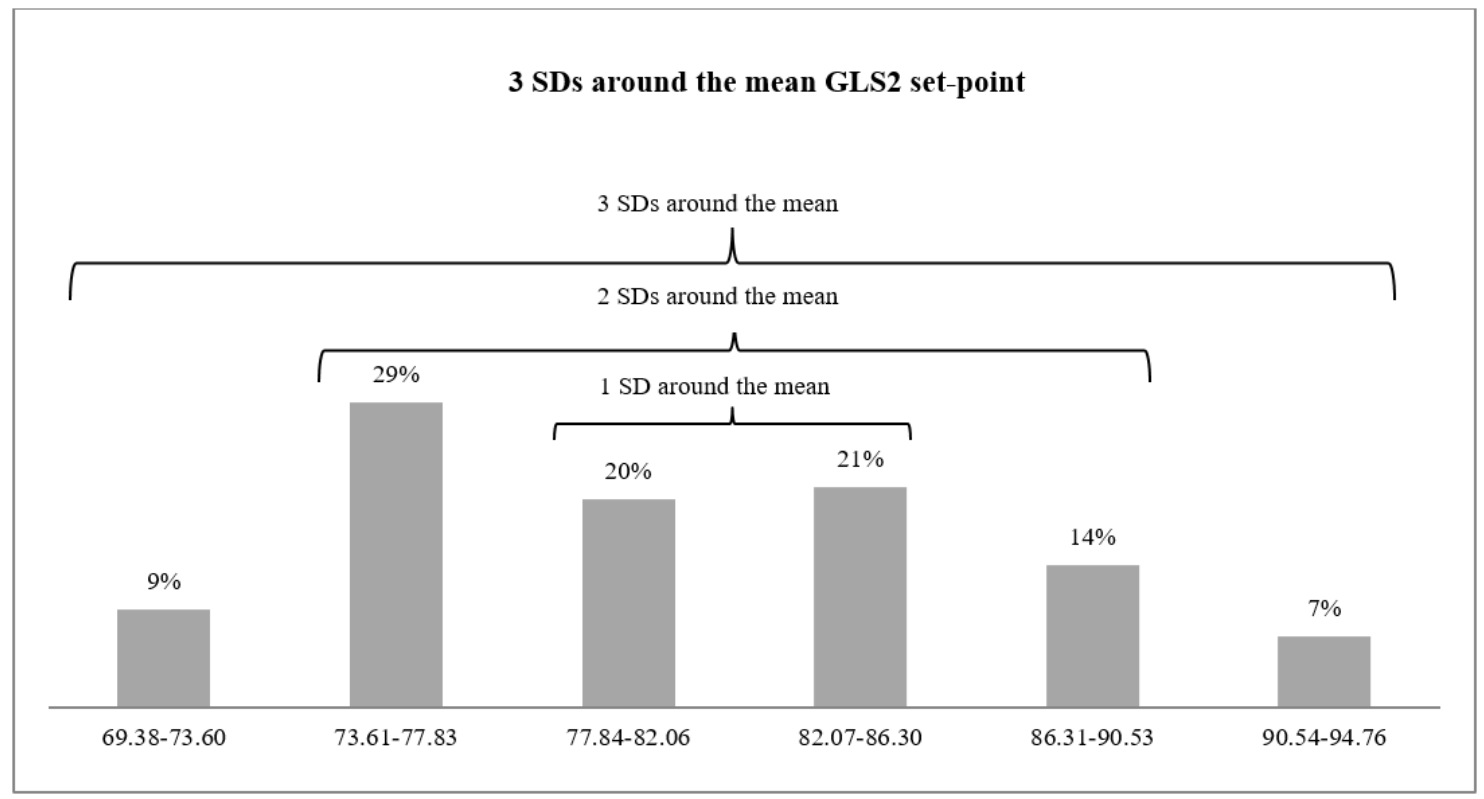

Figure 5 The distribution of HPMood set-points

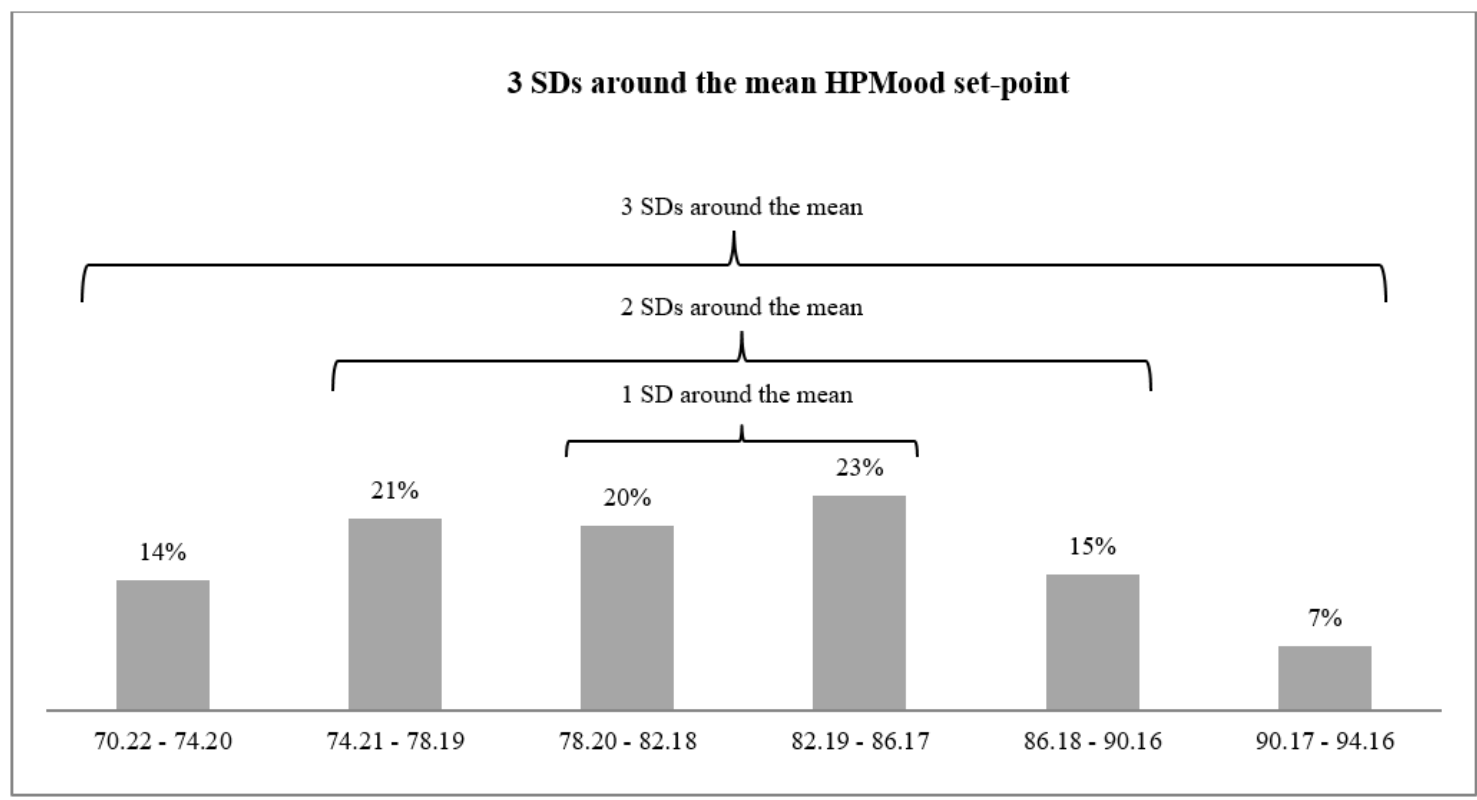




\section{University Library}

\section{- M M N E R VA A gateway to Melbourne's research publications}

Minerva Access is the Institutional Repository of The University of Melbourne

Author/s:

Capic, T;Li, N;Cummins, RA

Title:

Confirmation of Subjective Wellbeing Set-Points: Foundational for Subjective Social Indicators

Date:

2018-05-01

Citation:

Capic, T., Li, N. \& Cummins, R. A. (2018). Confirmation of Subjective Wellbeing Set-Points: Foundational for Subjective Social Indicators. SOCIAL INDICATORS RESEARCH, 137 (1), pp.1-28. https://doi.org/10.1007/s11205-017-1585-5.

Persistent Link:

http://hdl.handle.net/11343/283197 